\title{
Antioxidant Activity of Amino Acid Sodium and Potassium Salts in Vegetable Oils at Frying Temperatures
}

\author{
Hong-Sik Hwang ${ }^{1}$, Jill Winkler-Moser ${ }^{2}$, and Sean Liu ${ }^{2}$ \\ ${ }^{1}$ NCAUR, ARS, USDA \\ ${ }^{2} \mathrm{USDA} / \mathrm{ARS} / \mathrm{NCAUR}$
}

December 11, 2021

\begin{abstract}
Previous studies reported that several amino acids had strong antioxidant activity in vegetable oils under frying conditions. In this study, the carboxylic acid group of amino acids was converted to a carboxylate group (-COO-Na + or $-\mathrm{COO}-\mathrm{K}+$ ), a heating study was conducted with amino acid salts in soybean oil at $180{ }^{\circ} \mathrm{C}$. Sodium salts of amino acids including alanine, phenylalanine, and proline and disodium glutamate had significantly stronger antioxidant activity than the corresponding amino acids, and potassium salts had stronger antioxidant activity than sodium salts. Potassium salts of alanine and phenylalanine more effectively retained tocopherols in soybean oil than the corresponding amino acids during heating. Phenylalanine potassium salt had stronger antioxidant activity than phenylalanine in other vegetable oils including olive, high oleic soybean, canola, avocado, and corn oils. Phenylalanine potassium salt at 5.5. mM more effectively prevented oil oxidation than tert-butyl hydroquinone (TBHQ), a synthetic antioxidant, at its legal concentration limit $(0.02 \%)$ indicating its feasibility as a new antioxidant for frying.
\end{abstract}

\section{INTRODUCTION}

Frying is a popular cooking method, which causes deterioration of oil quality and formation of toxic oxidation products (Guillén \& Uriarte, 2012). Vegetable oils containing high levels of unsaturated fatty acids have many health benefits, yet they are prone to oxidation due to those unsaturated fatty acids (Choe \& Min, 2006). In the past, hydrogenation has been used to decrease unsaturation in oil to decrease the oxidation rate. However, this process generates trans fats, which are associated with the development of cardiovascular disease (Angell et al., 2009). Many manufacturers of fried foods have switched to oils containing high levels of saturated fatty acids in response to recent regulations requiring removal of trans fats in food products, although highly saturated fats are less desirable for human health than vegetable oils containing high contents of unsaturated fatty acids (Karupaiah \& Sundram, 2007). To use vegetable oils such as soybean oil for frying, strong antioxidants are needed to prevent their oxidation during frying. Generally, synthetic antioxidants are strong antioxidants and widely used for frying, of which the maximum concentration is limited by law to $0.02 \%$ of the total lipids due to potential toxicity (Ito, et al., 1986).

Amino acids are reported to have antioxidant activity in edible oils, which was attributed to synergism with tocopherols (Marcuse, 1962; Seher \& Löschner, 1986), chelation of metals (Decker, et al., 2001), and radical scavenging activity (Marcuse, 1960). Earlier studies conducted with emulsion systems because amino acids are soluble in water, but not in oil (Marcuse, 1960, 1962; Riisom, Sims, \& Fioriti, 1980). Recent studies found that amino acids were very effective in preventing oil oxidation at frying temperatures when they were directly added as powder in oil and that amino acids containing a thiol, thioether, or amine group had stronger activity than other amino acids (Heng, Ong, \& Chow, 2020; Hwang \& Winkler-Moser, 2017). Methionine effectively prevented the oxidation of soybean, olive, corn, peanut, high oleic soybean, canola, and sunflower oils at $180^{\circ} \mathrm{C}$ (Hwang, Winkler-Moser, \& Liu, 2019). 
Two major functional groups in amino acid are amine $\left(-\mathrm{NH}_{2}\right.$ or $\left.-\mathrm{NH}\right)$ and carboxylic acid (-COOH) groups. Amines are known to have radical scavenging activity and to produce new antioxidants by reactions with oxidation products during heating (Farag, et al., 1978; Choe \& Min, 2009). However, in general, a carboxylic acid group in an antioxidant negatively affects its antioxidant activity, and the conversion of the carboxylic acid to a methyl or ethyl ester increases the antioxidant activity. For example, when the carboxylic acid group of gallic acid and protocatechuic acid was converted to a methyl or ethyl ester, the antioxidant activity increased in fish oil and its emulsion (Asnaashari, Farhoosh, \& Sharif, 2014; Farhoosh, et al., 2016). In addition, when ferulic acid was converted to methyl ferulate, its antioxidant activity increased in a $\beta$ carotene-linoleate model system (Karamać, et al., 2005). The methyl ester of $\beta$-alanine also more effectively protected SBO from oxidation than $\beta$-alanine in a heating study at $180{ }^{\circ} \mathrm{C}$ (Hwang, et al., 2019). Miura et al. (Miura, et al., 2014) reported that when the carboxylic acid group of cysteine derivatives was converted to the carboxylate group by mixing the cysteine derivatives in situ with triethylamine, their antioxidant activity in methyl linoleate at $36{ }^{\circ} \mathrm{C}$ increased.

In this study, sodium or potassium salts of several amino acids were prepared as powder, suspended in soybean oil, and were evaluated for their antioxidant activities in SBO at $180{ }^{\circ} \mathrm{C}$ in comparison with the corresponding amino acids. Oxidation of oil was evaluated by analyzing polymerized triacylglycerols (PTAG) using gel permeation chromatography (GPC). Losses of reactive protons including olefinic, allylic, and bisallylic protons in NMR spectrum of oil were also evaluated, which are known to be reliable markers for oil oxidation (Hwang et al., 2017; Pignitter \& Somoza, 2012).

\section{MATERIAL AND METHODS}

\section{Materials}

SBO (Crisco ${ }^{\circledR}$, refined), olive (Bertolli ${ }^{\circledR}$, cooking oil), canola oil (Crisco ${ }^{\circledR}$ ), avocado oil (Spectrum Culinary ${ }^{\circledR}$, refined), and corn oil (Mazola $\left.{ }^{\circledR}\right)$ were purchased from a grocery store in Peoria, IL, USA. High oleic soybean oil (HO SBO, Plenish ${ }^{\circledR}$ ) was provided by DuPont (Johnston, IA, USA). Aluminum oxide, amino acids, food grade mixed tocopherols, and monosodium L-glutamate were obtained from SigmaAldrich (St. Louis, Missouri, USA). According to the certificate of analysis from the manufacture, the mixed tocopherols contains $13.2 \% \alpha-, 0.16 \% \beta-, 42.9 \% \gamma$-, and $16.3 \% \delta$-tocopherols in weight $(74.0 \%$ total). Considering the purity $(74.0 \%)$, the factor 1.35 was used to obtain an accurate concentration of mixed tocopherols in oil. L-Proline sodium salt was purchased from Combi-Blocks (San Diego, CA, USA). TBHQ, sodium hydroxide $(\mathrm{NaOH})$, and potassium hydroxide $(\mathrm{KOH})$ were purchased from Fluka (Deisenhofen, Germany). Tetrahydrofuran (THF), dichloromethane, ethanol, and hexane were obtained from Fisher Scientific (Fair Lawn, NJ, USA).

\section{Amino acid salts}

Except for two commercially available sodium salts, monosodium L-glutamate and L-proline sodium salt, amino acid salts were prepared following the previous methods (Dai, et al., 2019; Jiang, 1969). In this study, a crystallization step was added to obtain crystalline solids (steps 3-6 in the following procedure). A general procedure is: 1) Alanine $(3.0 \mathrm{~g}, 33.7 \mathrm{mmol})$ was weighed in a $250 \mathrm{ml}$ round bottom flask and $25 \%$ (wt.) $\mathrm{NaOH}$ solution (5.39 g, $33.7 \mathrm{mmol})$ was added. 2) Water $(2 \mathrm{~g})$ was added, and alanine was completely dissolved in the solution. 3) When ethanol $(100 \mathrm{ml})$ was added, precipitates were formed. 4) The volume of the solution was reduced to about $10 \mathrm{ml}$ using a rotary evaporator at $30{ }^{\circ} \mathrm{C}$, and ethanol $(100 \mathrm{ml})$ was added. This step was repeated twice more. 5) At the end of the step 4, $30 \mathrm{ml}$ of ethanol was added in the flask instead of $100 \mathrm{ml}$, which was then placed in a freezer $\left(-20^{\circ} \mathrm{C}\right)$ for $1 \mathrm{~h}$. 6) Solid was filtered and dried under vacuum overnight. Hereafter we use the acronym, amino acid $\mathrm{Na}$ or $\mathrm{K}$ for sodium or potassium salt of an amino acid. For example, "alanine Na" refers to the sodium salt of alanine. Alanine Na (2.20 g, $58.8 \%$ yield) was obtained as white powder. Arginine $\mathrm{Na}$ (2.69 g, 79.6\%), asparagine $\mathrm{Na}(2.29 \mathrm{~g}, 65.4 \%)$, glutamic acid di-Na $(2.12,54.1 \%)$, phenylalanine $\mathrm{Na}(2.20 \mathrm{~g}, 64.7 \%)$, and tyrosine $\mathrm{Na}(2.83 \mathrm{~g}, 84.1 \%)$ were obtained by this method. It should be noted that this study did not attempt to optimize the yields, but focused more on producing fine powder. Glutamine Na did not form crystalline solids. To obtain powder of Glutamine Na, 
after step 6, all the solvent was evaporated using the rotary evaporator followed by further drying using a vacuum pump overnight, and the solid was scraped off the round bottom flask.

Amino acid potassium salts were prepared following the general procedure used for sodium salts, but with an equimolar amount of $25 \%$ (wt.) KOH solution. Alanine K (2.82 g, 65.8\%), glutamine K (1.89 g, 50.0\%), phenylalanine $\mathrm{K}(2.10 \mathrm{~g}, 56.9 \%)$, and proline $\mathrm{K}(2.35 \mathrm{~g}, 58.9 \%)$ were obtained. Other amino acid potassium salts such as arginine $\mathrm{K}$, asparagine $\mathrm{K}$, glutamic acid $\mathrm{K}$, glutamic acid di-K, and tyrosine $\mathrm{K}$ were also prepared, but they were hygroscopic, did not make powder, and could not be dispersed in oil. The purpose of this study is to compare the antioxidant activity of amino acid salts with the corresponding amino acids, which were dispersed in oil. However, amino acid salts that cannot be dispersed in oil as power cannot be compared with the corresponding amino acids under the same conditions. Therefore, these amino acids were not included in this study.

\section{Thermogravimetric analysis (TGA)}

Since amino acid salts were prepared from an aqueous solution and two commercial amino acid salts were reported to contain water, the water content was determined by TGA, which was then used for an accurate concentration of amino acid in oil. A Model Q50 TGA (TA instruments, New Castle, DE, USA) was used for TGA experiments. The sample $(8-10 \mathrm{mg})$ was weighed onto a platinum sample pan and loaded with the autosampler. The temperature was increased at a rate of $20{ }^{\circ} \mathrm{C} / \mathrm{min}$ from $25{ }^{\circ} \mathrm{C}$ to $250{ }^{\circ} \mathrm{C}$ and nitrogen was blown into the sample chamber at a flow rate of $60 \mathrm{ml} / \mathrm{min}$ during measurements. Universal Analysis software was used to analyze data. The weight loss was recorded at the temperature where dehydration was completed (typically at $120-180{ }^{\circ} \mathrm{C}$ ). The experiments were conducted in duplicate, and results are shown in Supplementary Table 1.

\section{Heating studies}

Amino acid salts or amino acids $(0.039 \mathrm{mmol})$ were added as powder in SBO or other oils $(6.5 \mathrm{~g})$ in a vial to achieve $5.5 \mathrm{mM}$ concentration. While the solution was stirred with a magnetic bar to form a suspension, 2 grams of the suspension was transferred to a vial (26.2 $\mathrm{mm}$ i.d., $60 \mathrm{~mm}$ height). Three samples per treatment were prepared. The ratio of surface area to volume of oil in this vial was approximately $2.5 \mathrm{~cm}^{2} / \mathrm{cm}^{3}$. The cap of the vial was removed, and the samples were heated in an oven at $180{ }^{\circ} \mathrm{C}$ for $8 \mathrm{~h}$. Oil samples were then transferred to 1-dram vials and stored at -20 until analyses. The oxidation of oil was determined in a week after heating.

\section{Stripped SBO}

While SBO was used as received for all other heating studies, stripped SBO, in which tocopherols and other polar compounds were removed, was used for the interaction studies with tocopherols. Stripped SBO was prepared by passing SBO through an aluminum oxide column using hexane as solvent as described in the previous study (Hwang et al., 2017). About $100 \mathrm{ml}$ hexane was added to a glass column, and $200 \mathrm{~g}$ dry aluminum oxide was slowly added. Hexane was drained, and sand was added to form a thin layer. SBO $(300 \mathrm{~g})$ and hexane $(300 \mathrm{ml})$ were mixed, added to the column, and collected into a round-bottom flask, where argon was gently blown to prevent oxidation of stripped oil. After the SBO solution was drained, the column was further eluted with additional hexane $(500 \mathrm{ml})$. The solvent was removed with a rotary evaporator followed by high vacuum. The previous procedure (Hwang et al., 2017) was followed to confirm the removell of ttocopherols in oil using HPLC. The stripped SBO was stored at $-20 \mathrm{oC}$ under argon until the heating study.

\section{PTAG}

Shimadzu LC20AT HPLC (Kyoto, Japan) was used to determine PTAG in oxidized oil following the previously reported method (Hwang, et al., 2014). Oil sample dissolved in dichloromethane (about $10 \mathrm{mg}$ oil in $10 \mathrm{ml}$ dichloromethane) was transferred to an autosampler vial, and the solution $(10 \mu \mathrm{l})$ was injected into a size exclusion column (PLGel, $5 \mu \mathrm{m}, 300 \times 7.5 \mathrm{~mm}, 100 \AA$ pore size, Polymer Labs, Amherst, MA, USA). A Sedex model 75 evaporative light scattering detector (ELSD) (Sedere, Inc., Cranbury, NJ, USA) 
was used as detector. The operation temperature of ELSD was $40{ }^{\circ} \mathrm{C}$, and nebulizer gas was nitrogen (3.5 bar). Percentages of peaks in chromatograms are reported.

\section{NMR analysis}

Oil oxidation was evaluated with the previously reported NMR method (Hwang et al., 2017). Oil samples were dissolved in $\mathrm{CDCl}_{3}$, and spectra were taken with a Bruker Avance 500 spectrometer (Bruker Biospin, Billerica, MA, USA). Signals were analyzed with SpinWorks 4 software (Chemistry NMR Lab, Winnipeg, MB, Canada). Signal intensities of olefinic protons (olefinic H) at 5.29-5.46 ppm, bisallylic protons (bisallylic $\mathrm{H}$ ) at 2.70-2.88 ppm, and allylic protons (allylic $\mathrm{H}$ ) at $1.94-2.15 \mathrm{ppm}$ were determined. While olefinic $\mathrm{H}$ and bisallylic $\mathrm{H}$ were used to assess the oxidation of SBO and corn oil because these two signals had biggest changes during oxidation, the loss of allylic $\mathrm{H}$ was used in place of bisallylic $\mathrm{H}$ for high oleic oils including olive oil, canola oil, HO SBO, and avocado oil because their bisallylic $\mathrm{H}$ signals were too small.

\section{Fatty acid composition analysis}

The previously reported method (Ichihara, et al., 1996) was followed to convert oil samples to fatty acid methyl esters, which were analyzed by gas chromatography (GC). Oil sample (10 mg) was dissolved in hexane (about $1.4 \mathrm{ml}$ ), and $2 \mathrm{~N} \mathrm{KOH}$ in methanol $(200 \mu \mathrm{L}$ ) was added. The solution was shaken with a Vortex mixer for $2 \mathrm{~min}$ and allowed to separate into two phases. The hexane layer (top layer) was added to autosampler vials, and the solution $(1 \mu \mathrm{l}$ ) was injected into a capillary column (Supelco SP-2560, $100 \mathrm{~m} \times 0.25 \mathrm{~mm}, 0.20$ $\mu \mathrm{m}$ film, Bellefonte, PA, USA) linked to Shimadzu GC 2010 (Columbia, MD, USA). The program was set to have the initial temperature at $165{ }^{\circ} \mathrm{C}$ for $30 \mathrm{~min}$, then to increase at a rate of $2{ }^{\circ} \mathrm{C} / \mathrm{min}$ to $200{ }^{\circ} \mathrm{C}$, and to hold at $200{ }^{\circ} \mathrm{C}$ for $12 \mathrm{~min}$. Helium (carrier gas) flow rate was $2.0 \mathrm{ml} / \mathrm{min}$, the injector temperature was $250{ }^{\circ} \mathrm{C}$, the FID temperature was $250{ }^{\circ} \mathrm{C}$, and the split ratio was $1: 100$. Fatty acid methyl esters peaks were identified using commercial standards.

\section{Tocopherol analysis}

Tocopherols in oil was determined with an HPLC (Shimadzu Prominence iSeries, Kyoto, Japan) equipped photodiode array (PDA) and a fluorescence detector in series (Hwang et al., 2017). Oil sample (about $10 \mathrm{mg}$ ) dissolved in hexane:THF $(97: 3 \mathrm{v} / \mathrm{v}, 1 \mathrm{ml})$ was injected to onto a YMC-Pack Diol 120 NP column $(150 \mathrm{x} 3.0$ $\mathrm{mm}, 5 \mu \mathrm{m}$, YMC America, Allentown, PA, USA) and eluted with hexane/THF (97:3 v/v) at a flow rate of 1.0 $\mathrm{ml} / \mathrm{min}$. The PDA was set to scan from $200-500 \mathrm{~nm}$ and collect data at $295 \mathrm{~nm}$ for tocopherol verification. Quantitation was performed with the fluorescence detector set at $344 \mathrm{~nm}$ (emission) after excitation at 292 $\mathrm{nm}$. Each tocopherol was identified using commercial standards. External standard curves per tocopherol were used for quantitative analysis.

\section{Micro-frying of potato cubes}

Micro-frying study was conducted with potato cubes following the previously reported method (Hwang, et al., 2013), which was slightly modified in the current study. Amino acid or amino acid salt (5.5 mM) and SBO $(20.0 \mathrm{~g})$ were weighed in a beaker and stirred with a magnetic bar to form a suspension. The suspension $(6.0 \mathrm{~g})$ was transferred to the same vial used for the heating study. For TBHQ, which is soluble in SBO, $0.02 \%(\mathrm{w} / \mathrm{w})$ was dissolved in $20.0 \mathrm{~g}$ SBO, and the solution $(6.0 \mathrm{~g})$ was transferred to the vial. The ratio of surface area to volume of oil in this vial was $0.82 \mathrm{~cm}^{2} / \mathrm{cm}^{3}$. A potato was peeled, cut into $0.6 \mathrm{~cm} \times 0.6$ $\mathrm{cm}$ cubes, and soaked in DI water until frying. Vials were randomly placed in an oil bath, of which the temperature was maintained at $180{ }^{\circ} \mathrm{C}$ on a hotplate using a temperature probe placed in the oil bath. After $1 \mathrm{~h}$, the potato cube attached to the tip of a glass pipette was fried for 4 min every 20 min five times. After a $2 \mathrm{~h}$ and $40 \mathrm{~min}$ break while oil was heated at $180^{\circ} \mathrm{C}$, frying was continued another five times in the same way. The oil was, then, left at $180^{\circ} \mathrm{C}$ for $1 \mathrm{~h}$ and $40 \mathrm{~min}$. In this procedure, the total heating time was $8 \mathrm{~h}$, and the total number of frying was 10 times. Oil samples were transferred to 1-dram vials and stored at -20 ${ }^{o} \mathrm{C}$ until analyses. The oxidation of oil was determined in a week after frying.

\section{Statistical analysis}


Three experimental replicates were carried out for heating and frying studies. Since several sets of heating experiments were conducted in different days, control SBO samples were included in each set of heating experiments, which were then used for normalization of PTAG and NMR data. Two experimental replicates were carried out for heating studies for the synergistic effect and for the activity in five other vegetable oils. PTAG, fatty acid composition, and tocopherols were determined at least in duplicate. Data were analyzed with one-way analysis of variance (ANOVA) and Tukey-Kramer Honestly Significant Difference test at $P<$ 0.05 using JMP 15 program (SAS Institute, Cary, NC, USA). Multivariate correlation analysis was conducted with the same program.

\section{RESULTS AND DISCUSSION}

\section{Amino acid salts}

Figure 1 shows the reaction of amino acids with $\mathrm{NaOH}$ or $\mathrm{KOH}$ to produce amino acid salts and molecular structures of amino acids used in the present study. Although the apparent change by this reaction was to convert the carboxylic acid group to sodium or potassium carboxylate group, since amino acids exist as Zwitterions in a neutral aqueous solution and in solid state (Sinha, et al., 2013), the other way to describe this reaction is that the ammonium group $\left(-\mathrm{NH}_{3}{ }^{+}\right)$of the Zwitterion was converted to an amino group ($\mathrm{NH}_{2}$ ) while the cation of the base $\left(\mathrm{Na}^{+}\right.$or $\left.\mathrm{K}^{+}\right)$bound the carboxylate $\left(-\mathrm{COO}^{-}\right)$. We hypothesized that these amino acid salts would have stronger antioxidant activity than the corresponding amino acids because the resultant amino group can inhibit the oxidation of oil by its radical scavenging activity and by antioxidants produced from reactions with oxidation products (Farag, et al., 1978; Choe \& Min, 2009) and the conversion of the carboxylic acid group to the carboxylate group can improve the antioxidant activity by preventing the negative effect of the carboxylic acid group.

For glutamic acid containing two carboxylic acid groups, glutamic acid di-sodium salt was also prepared by adding two molar equivalent amounts of $\mathrm{NaOH}$. Nine amino acid sodium salts and four potassium salts were prepared as powder. Yields ranged from 54.1 to $84.1 \%$ for sodium salts and from 50.0 to $65.8 \%$ for potassium salts. It should be noted that the yields can be further optimized since this study did not attempt to optimize the yields but more focused on producing fine powder.

\section{Heating study at $180{ }^{\circ} \mathrm{C}$}

It has been a problem that most conventional methods for lipid oxidation assessment detect either primary or secondary oxidation products, which often lead to inconsistent conclusions (Gray, 1978). In-vitroantioxidation activity tests determining the radical scavenging ability of an antioxidant do not well correlate with the antioxidant activity under frying conditions because these tests are typically conducted at room temperature (Hwang et al., 2012). Among many analytical methods, NMR, HPLC, and size-exclusion chromatography methods are known to be the most reliable methods (Pignitter \& Somoza, 2012). Recently, an NMR method specifically designed for the assessment of frying oils has been developed, which was found to reliable, and to be faster and more convenient than other conventional methods (Hwang et al., 2017). Therefore, in this study, PTAG using the size-exclusion chromatography and the NMR method were used to determine oil oxidation (Table 1). The results with an amino acid salt were compared with those of the corresponding amino acid, TBHQ, and control, and they were marked with letters, a, t, and c, respectively when the mean values were significantly different $(\mathrm{P}<0.05)$. When the values of an amino acid potassium salt were significantly different from those of the corresponding sodium salt, they were marked with a letter $n$.

Alanine $\mathrm{Na}$, glutamic acid di-Na, phenylalanine $\mathrm{Na}$, and proline $\mathrm{Na}$ had significantly higher antioxidant activity compared to their corresponding amino acids resulting in lower losses of olefinic $\mathrm{H}$ and bisallylic $\mathrm{H}$ and PTAG. Arginine Na, asparagine Na, glutamic acid Na, and tyrosine Na prevented oxidation of SBO slightly better than their corresponding amino acids. The antioxidant activity order of glutamic acid and its mono- and di-sodium salts was di-sodium salt $>$ mono sodium salt $>$ glutamic acid indicating that the activity was the highest when all the carboxylic acid groups were converted to carboxylate groups. Antioxidant activity of glutamine $\mathrm{Na}$ was not stronger than that of glutamine. This indicates that not all the amino acid salts have stronger antioxidant activity than the corresponding amino acids, for which the 
reason is not clear at the present stage. Further studies with more amino acid salts will be needed to fully understand the effectiveness of amino acid salts.

Potassium salts tested in this study had even stronger antioxidant activity than sodium salts. Especially, alanine $\mathrm{K}$ and phenylamine $\mathrm{K}$ had significantly lower losses of reactive protons (olefinic $\mathrm{H}$ and bisallylic $\mathrm{H}$ ) and PTAG than their corresponding amino acids. It can be explained by higher lipophilicity of potassium salts than sodium salts (Yamaguchi et al., 1995) since it was reported that more lipophilic amino acids had stronger activity than less lipophilic ones (Hwang, et al., 2019). It is noteworthy that the effectiveness of 5.5 $\mathrm{mM}$ alanine $\mathrm{K}$, phenylalanine $\mathrm{K}$, and proline $\mathrm{K}$ in preventing the oxidation of SBO was greater than $0.02 \%$ (1.1 mM) TBHQ.

\section{Retention of tocopherols}

In the previous study (Hwang et al., 2017), it was found that amino acids having stronger antioxidant activity more effectively retained tocopherols in SBO, and that retention of tocopherols was one important factor for effectiveness in preventing the oxidation of oil. To examine whether the stronger antioxidant activity of amino acid salts over the corresponding amino acids was attributed to better retention of tocopherols during heating studies, tocopherols in SBO containing $5.5 \mathrm{mM}$ alanine, alanine $\mathrm{K}$, phenylalanine, or phenylalanine $\mathrm{K}$ were analyzed after 2,4 , and $8 \mathrm{~h}$ at $180{ }^{\circ} \mathrm{C}$.

Figure 2 shows the concentrations of three tocopherols $(\alpha-, \gamma$-, and $\delta$-tocopherols) remained in SBO during heating. Average values at $2 \mathrm{~h}$ and $4 \mathrm{~h}$ were compared by Tukey-Kramer Honestly Significant Difference test $(\mathrm{P}<0.05)$. At $4 \mathrm{~h}$, no $\alpha$-tocopherol remained in the control SBO while $7.2 \% \gamma$-tocopherol and $35.3 \%$ $\delta$-tocopherol were left. Alanine did not improve the retention of $\alpha$-tocopherol, but slightly improved the retention of $\gamma$-tocopherol and $\delta$-tocopherol at $2 \mathrm{~h}$ (Figs. 2a-2c). At $4 \mathrm{~h}, \mathrm{SBO}$ with alanine did not have higher concentrations of tocopherols than the control and the concentration of $\delta$-tocopherol was even lower than that in the control at $8 \mathrm{~h}$. This result is somewhat different from the previous study (Hwang et al., 2017), which reported that alanine was effective in retaining tocopherols throughout the course of the heating study. This difference might have been caused by different sources of alanine and SBO and the heating environments such as humidity. Nevertheless, it is noteworthy that alanine K retained the three tocopherols significantly better than alanine (Figs. 2a-2c) indicating that the stronger antioxidant activity of alanine $\mathrm{K}$ than alanine is attributed to better retention of tocopherols in SBO. Phenylalanine effectively retained tocopherols except for $\delta$-tocopherol at $8 \mathrm{~h}$ (Figs. 2d-2f). Phenylalanine $\mathrm{K}$ retained tocopherols significantly better than phenylalanine confirming that the stronger antioxidant activity of potassium salt of amino acids is attributed to better retention of tocopherols than the corresponding amino acids.

\section{Synergistic effect with tocopherols}

The previous study (Hwang et al., 2017) found that the activity of amino acids in the absence of tocopherols was negligible while it remarkably increased in the presence of tocopherols, which indicated that the synergistic effect with tocopherols was an important mechanism for antioxidant activity of amino acids at frying temperatures. In this study, the synergistic effect of amino acid salts with mixed tocopherols was compared to that of the corresponding amino acids to examine if the improved activity of the amino acid salts was related to the synergism. The study was conducted by adding known amounts of mixed tocopherols and amino acid or amino acid salt in stripped SBO where inherent tocopherols and other polar compounds were removed. Since the previous study showed that the synergistic effect was most clearly shown when the ratio of amino acid and tocopherol was 1:1 and the heating time was $2 \mathrm{~h}$ (Hwang et al., 2017), these conditions were used in this study. The three strongest antioxidants, alanine $\mathrm{K}$, phenylalanine $\mathrm{K}$ and proline $\mathrm{K}$ were chosen for this experiment.

Figure 3 shows results of the heating study with alanine $\mathrm{K}$, phenylalanine $\mathrm{K}$, and proline $\mathrm{K}$ with or without mixed tocopherols in stripped SBO in comparison with the corresponding amino acids. The loss of bisallylic $\mathrm{H}$, of which the trend was very similar to that of olefinic $\mathrm{H}$ was not presented in Figure 3. Activities of amino acids and amino acid salts were very low in the absence of tocopherols while their 1:1 mixtures with tocopherols had strong antioxidant activity was consistent with the previous report while their effectiveness 
was not as strong as arginine and lysine (Hwang et al., 2017). From Figures 3a and 3b, it was found that the antioxidant activity of alanine $\mathrm{K}$ did not differ from that of alanine in the absence of tocopherols, but it was significantly stronger when combined with the same molar concentration of tocopherols indicating that synergism with tocopherols was a cause for the improved antioxidant activity of amino acid salts. The loss of olefinic $\mathrm{H}$ in phenylalanine and phenylalanine $\mathrm{K}$ treatments (Fig. 3c) followed the same trend indicating that phenylalanine $\mathrm{K}$ had greater synergism with tocopherols than phenylalanine. However, PTAG of phenylalanine K (Fig. 3d) did not show this trend. Since the effectiveness of 2.75 mM phenylalanine K without tocopherols in preventing the formation of PTAG was significantly greater than that of $2.75 \mathrm{mM}$ phenylalanine, it could not be concluded whether the stronger activity of phenylalanine $\mathrm{K}$ than phenylalanine in the presence of tocopherols was due to the greater synergism or just due to an additive effect. Proline K without tocopherols also showed significantly stronger antioxidant activity than proline alone (Figs. 3e and 3f). Proline $\mathrm{K}$ also had stronger activity than proline in the presence of tocopherols, but the magnitude of the difference between results of proline $\mathrm{K}$ and proline was not greater than that in the absence of tocopherols. This indicates that proline $\mathrm{K}$ did not have greater synergism with tocopherols than proline. The intrinsic antioxidant activity was improved by converting the carboxylic acid group to potassium carboxylate group of proline, which was shown in the absence of tocopherols, and the improved activity was directly reflected in its antioxidant activity in the presence of tocopherols. Therefore, with the given data, it seemed that an improved synergistic effect with tocopherols or an improved intrinsic antioxidant activity of amino acid salt played a role in the improved activity of amino acid salts, in addition to their better retention of tocopherols discussed in Section 3.3. Further studies on amino acid salts are needed to better understand their activity and mechanisms.

\section{Micro-frying study}

The antioxidant activity of alanine $\mathrm{K}$ and phenylalanine $\mathrm{K}$ compared to that of the corresponding amino acids was examined in a frying study, where potato cubes were fried in a vial containing $6 \mathrm{~g} \mathrm{SBO}$ at $180{ }^{\circ} \mathrm{C}$. Losses of olefinic $\mathrm{H}$ and bisallylic $\mathrm{H}$ and formation of PTAG during frying are shown in Figure 4 . Alanine $\mathrm{K}$ had stronger antioxidant activity than alanine showing significantly lower loss of olefinic $\mathrm{H}$ while differences in loss of bisallylic $\mathrm{H}$ and PTAG were not significant. Phenylalanine $\mathrm{K}$ gave significantly lower losses of olefinic $\mathrm{H}$ and bisallylic $\mathrm{H}$ and PTAG compared to phenylalanine. It should be noted that although the activity of $5.5 \mathrm{mM}$ phenylalanine was lower than $0.02 \%(1.1 \mathrm{mM}) \mathrm{TBHQ}$, its potassium salt had significantly higher activity than TBHQ.

\section{Antioxidant activity in other vegetable oils}

Antioxidant activity of phenylalanine $\mathrm{K}$ was also compared with that of phenylalanine in other vegetable oils. High oleic oils including olive oil, canola oil, HO SBO, and avocado oil, which draw great interest as frying oils due to their oxidative stability, were chosen in this study. Corn oil, which is widely used as frying oil, was also chosen. Table 2 shows fatty acid composition and tocopherols in these oils. Trace amounts of minor fatty acids including C11:0, C14:0, C15:0, C17:0, C18:2 (c9, t12), C18:2 (t9, c12), C18:3 (9,12,15), and C20:1 (c11) were also detected in some oils, but they are not listed in Table 2.

Table 3 shows the heating study results with $5.5 \mathrm{mM}$ phenylalanine or phenylalanine $\mathrm{K}$ in these vegetable oils at $180{ }^{\circ} \mathrm{C}$. Due to the very small bisallylic $\mathrm{H}$ signal in olive oil, canola oil, HO SBO, and avocado oil, loss of allylic $\mathrm{H}$ was determined instead of bisallylic $\mathrm{H}$ for these oils. Phenylalanine $\mathrm{K}$ had significantly stronger antioxidant activity than phenylalanine in olive oil and HO SBO. It showed slightly stronger activity than phenylalanine in canola oil, avocado oil, and corn oil. It is noteworthy that phenylalanine $\mathrm{K}$ had very strong antioxidant activity in $\mathrm{HO}$ SBO showing very low losses of olefinic $\mathrm{H}$ and allylic $\mathrm{H}(2.43 \%$ and $0.95 \%$, respectively) and PTAG (1.26\%) compared the control oil (13.27\% loss of olefinic, 9.62\% loss of allylic H, and $9.45 \%$ PTAG).

Understanding what made phenylalanine $\mathrm{K}$ more effective in some oils than in other oils would be very useful for the development of new natural antioxidants. For that, correlation tests were conducted between loss of olefinic H and PTAG using \%improvements from control and three major fatty acids (C16:0, C18:1 (c9), 
and C18:2 (c9,12)), ratio of saturated fatty acids to unsaturated fatty acids, three major tocopherols $(\alpha-$, $\gamma$-, and $\delta$-), and total tocopherols (Table 4). No correlation of the antioxidant activity with any fatty acid or the ratio of saturated fatty acids to unsaturated fatty acids was observed. In contrast, $\delta$-tocopherol had relatively strong positive correlations with loss of olefinic $\mathrm{H}(\mathrm{r}=0.8823, \mathrm{p}=0.0200)$ and PTAG $(\mathrm{r}=0.8899$, $\mathrm{p}=0.0175)$ of phenylalanine and loss of olefinic $\mathrm{H}(\mathrm{r}=0.8432, \mathrm{p}=0.0349)$ and PTAG $(\mathrm{r}=0.8225, \mathrm{p}=$ $0.0445)$ of phenylalanine K. $\gamma$-Tocopherol had weak positive correlations with the antioxidant activity $(\mathrm{r}=$ $0.5869, \mathrm{p}=0.2207$ and $\mathrm{r}=0.6046, \mathrm{p}=0.2036$ for loss of olefinic $\mathrm{H}$ and PTAG of phenylalanine, respectively, and $\mathrm{r}=0.5305, \mathrm{p}=0.2789$ and $\mathrm{r}=0.3009, \mathrm{p}=0.5623$ for loss of olefinic $\mathrm{H}$ and PTAG of phenylalanine $\mathrm{K}$, respectively). The correlations with total tocopherols were weak but positive, indicating that the activity of phenylalanine and phenylalanine $\mathrm{K}$ is likely related to the concentration of tocopherols in oil. It is interesting that $\alpha$-tocopherol had negative correlations with loss of olefinic $\mathrm{H}(\mathrm{r}=-0.9200, \mathrm{p}=0.0094)$ and PTAG $(\mathrm{r}=$ $-0.7397, \mathrm{p}=0.0928)$ of phenylalanine and loss of olefinic $\mathrm{H}(\mathrm{r}=-0.8756, \mathrm{p}=0.0222)$ and PTAG $(\mathrm{r}=-0.7194$, $\mathrm{p}=0.1071$ ) of phenylalanine K. This was likely caused by the fact that the two oils, olive and avocado oils, with a high content of $\alpha$-tocopherol happened to have the lowest total tocopherols. Correlation tests in this study had a limitation that tests were conducted with only six oils, but the interesting trends found in this study could be further investigated, which can be important for the application of amino acid salts in frying oil.

\section{CONCLUSIONS}

Converting the carboxylic acid group of an amino acid into its sodium salt $\left(-\mathrm{COO}^{-} \mathrm{Na}^{+}\right)$or potassium salt $\left(-\mathrm{COO}^{-} \mathrm{K}^{+}\right)$increased its effectiveness in preventing the oxidation of $\mathrm{SBO}$ at $180{ }^{\circ} \mathrm{C}$. The antioxidant activity order of glutamic acid salts was di-sodium salt $>$ mono sodium salt $>$ glutamic acid further confirming that removing the negative effect of the carboxylic acid group increased the antioxidant activity. Potassium salts had stronger antioxidant activity than sodium salts, presumably, due to their higher lipophilicity than sodium salts. Alanine $\mathrm{K}$, phenylalanine $\mathrm{K}$ and proline $\mathrm{K}(5.5 \mathrm{mM})$ were more effective in preventing the oxidation of SBO than TBHQ $(0.02 \%, 1.1 \mathrm{mM})$ at $180{ }^{\circ} \mathrm{C}$. It was found that the stronger antioxidant activity of amino acid salts than the corresponding amino acids was attributed to their more effective retention of tocopherols in SBO. A study with mixtures of mixed tocopherols and alanine $\mathrm{K}$, phenylalanine $\mathrm{K}$, or proline $\mathrm{K}$ in stripped SBO indicated that the stronger antioxidant of amino acid salts than the corresponding amino acids was attributed to the synergistic effect with tocopherols or their stronger intrinsic activity. The strong activity of amino acid potassium salts was also confirmed in a frying study. Phenylalanine $\mathrm{K}$ was much more effective than phenylalanine in preventing the oxidation of other vegetable oils such as olive oil and high oleic soybean oil. It also had slightly stronger activity than phenylalanine in canola oil, avocado oil, and corn oil. This study showed that converting the carboxylic acid group of an amino acid to a sodium or potassium carboxylate group significantly improved the antioxidant activity of amino acid at frying temperatures. Further studies will focus on the preparation of more amino acid salts, their activities, and their effects on sensory properties of fried foods and on the formation of toxic volatiles.

\section{Acknowledgement}

The authors express appreciation to Cynthia Ruder and Julie Anderson for excellent technical support and Dr. Karl Vermillion for NMR spectra. This research was supported by the U.S. Department of Agriculture, Agricultural Research Service.

\section{REFERENCES}

Angell SY, Silver LD, Goldstein GP, Johnson CM, Deitcher DR, Frieden TR, et al. Cholesterol control beyond the clinic: New york city's trans fat restriction. Ann Intern Med. 2009;151:129-134. https://doi.org/10.7326/0003-4819-151-2-200907210-00010.

Asnaashari M, Farhoosh R, Sharif A. Antioxidant activity of gallic acid and methyl gallate in triacylglycerols of kilka fish oil and its oil-in-water emulsion. Food Chem. 2014;159:439-444. https://doi.org/https://doi.org/10.1016/j.foodchem.2014.03.038. 
Choe E, Min DB. Mechanisms and factors for edible oil oxidation. Compr Rev Food Sci Food Saf. 2006;5:169186. https://doi.org/10.1111/j.1541-4337.2006.00009.x.

Choe E, Min DB. Mechanisms of antioxidants in the oxidation of foods. Compr Rev Food Sci Food Saf. 2009;8:345-358. https://doi.org/10.1111/j.1541-4337.2009.00085.x.

Dai Z, Deng J, Ansaloni L, Janakiram S, Deng L. Thin-film-composite hollow fiber membranes containing amino acid salts as mobile carriers for $\mathrm{CO}_{2}$ separation. J Membr Sci. 2019;578:61-68. https://doi.org/10.1016/j.memsci.2019.02.023.

Decker EA, Ivanov V, Zhu B-Z, Frei B. Inhibition of low-density lipoprotein oxidation by carnosine and histidine. J Agric Food Chem. 2001;49:511-516. https://doi.org/10.1021/jf0010533.

Farag RS, Osman SA, HallaBo SAS, Girgis AN, Nasr AA. Linoleic acid oxidation catalyzed by various amino acids and cupric ions in freeze-dried model systems. J Am Oil Chem Soc. 1978;55:708-710. https://doi.org/10.1007/bf02665367.

Farhoosh R, Johnny S, Asnaashari M, Molaahmadibahraseman N, Sharif A. Structure-antioxidant activity relationships of o-hydroxyl, o-methoxy, and alkyl ester derivatives of p-hydroxybenzoic acid. Food Chem. 2016;194:128-134. https://doi.org/10.1016/j.foodchem.2015.08.003.

Gray JI. Measurement of lipid oxidation: A review. J Am Oil Chem Soc. 1978;55:539-546. https://doi.org/10.1007/BF02668066.

Guillén MD, Uriarte PS. Aldehydes contained in edible oils of a very different nature after prolonged heating at frying temperature: Presence of toxic oxygenated $\alpha, \beta$ unsaturated aldehydes. Food Chem. 2012;131:915926. https://doi.org/10.1016/j.foodchem.2011.09.079.

Heng HFE, Ong XL, Chow PYE. Antioxidant action and effectiveness of sulfur-containing amino acid during deep frying. J Food Sci Technol. 2020;57:1150-1157. https://doi.org/10.1007/s13197-019-04150-5.

Hwang H-S, Winkler-Moser J, Bakota E, Berhow M, Liu S. Antioxidant activity of sesamol in soybean oil under frying conditions. J Am Oil Chem Soc. 2013;90:659-666. https://doi.org/10.1007/s11746-013-2204-5.

Hwang H-S, Winkler-Moser JK. Antioxidant activity of amino acids in soybean oil at frying temperature: Structural effects and synergism with tocopherols. Food Chem. 2017;221:1168-1177. http://dx.doi.org/10.1016/j.foodchem.2016.11.042.

Hwang HS, Winkler-Moser JK, Doll KM, Gadgil M, Liu SX. Factors affecting antioxidant activity of amino acids in soybean oil at frying temperatures. Eur J Lipid Sci Technol. 2019;121. https://doi.org/10.1002/ejlt.201900091.

Hwang HS, Winkler-Moser JK, Kim Y, Liu SX. Antioxidant activity of spent coffee ground extracts toward soybean oil and fish oil. Eur J Lipid Sci Technol. 2019;121:1800372. https://doi.org/10.1002/ejlt.201800372.

Hwang HS, Winkler-Moser JK, Liu SX. Structural effect of lignans and sesamol on polymerization of soybean oil at frying temperature. J Am Oil Chem Soc. 2012;89:1067-1076. https://doi.org/10.1007/s11746-0111994-6.

Hwang HS, Winkler-Moser JK, Liu SX. Study on antioxidant activity of amino acids at frying temperatures and their interaction with rosemary extract, green tea extract, and ascorbic acid. J Food Sci. 2019;84:36143623. https://doi.org/10.1111/1750-3841.14963 .

Hwang HS, Winkler-Moser JK, Vermillion K, Liu SX. Enhancing antioxidant activity of sesamol at frying temperature by addition of additives through reducing volatility. J Food Sci. 2014;79:C2164-2173. https://doi.org/10.1111/1750-3841.12653.

Ichihara K, Shibahara A, Yamamoto K, Nakayama T. An improved method for rapid analysis of the fatty acids of glycerolipids. Lipids. 1996;31:535-539. https://doi.org/10.1007/BF02522648. 
Ito N, Hirose M, Fukushima S, Tsuda H, Shirai T, Tatematsu M. Studies on antioxidants: Their carcinogenic and modifying effects on chemical carcinogenesis. Food Chem Toxicol. 1986;24:1071-1082. https://doi.org/10.1016/0278-6915(86)90291-7.

Jiang DD. Amino acid salt articles and methods of making and using them. US 8,500,880 B2 (Patent) 2013.

Karamać M, Buciński A, Pegg RB, Amarowicz R. Antioxidant and antiradical activity of ferulates. Czech Food Sci. 2005;23:64-68. https://doi.org/10.17221/3373-CJFS.

Karupaiah T, Sundram K. Effects of stereospecific positioning of fatty acids in triacylglycerol structures in native and randomized fats: A review of their nutritional implications. Nutr Metab. 2007;4:16. https://doi.org/10.1186/1743-7075-4-16.

Marcuse. Antioxidative effect of amino-acids. 1960;186:886-887. http://dx.doi.org/10.1038/186886a0 .

Marcuse. The effect of some amino acids on the oxidation of linoleic acid and its methyl ester. J Am Oil Chem Soc. 1962;39:97-103. https://doi.org/10.1007/bf02631680.

Marcuse R. Antioxidative effect of amino-acids. Nature. 1960;186:886. https://doi.org/10.1038/186886a0.

Miura Y, Honda S, Masuda A, Masuda T. Antioxidant activities of cysteine derivatives against lipid oxidation in anhydrous media. Biosci Biotechnol Biochem. 2014;78:1452-1455. https://doi.org/10.1080/09168451.2014.918496.

Pignitter M, Somoza V. Critical evaluation of methods for the measurement of oxidative rancidity in vegetable oils. J Food Drug Anal. 2012;20:772-777. https://doi.org/10.38212/2224-6614.2024.

Riisom T, Sims RJ, Fioriti JA. Effect of amino acids on the autoxidation of safflower oil in emulsions. J Am Oil Chem Soc. 1980;57:354-359. https://doi.org/10.1007/bf02662057.

Seher A, Löschner D. Natürliche antioxidantien vi aminosäure-gemische als effiziente synergisten. Fette Wiss Technol. 1986;88:1-6. https://doi.org/10.1002/lipi.19860880102.

Sinha L, Karabacak M, Narayan V, Cinar M, Prasad O. Molecular structure, electronic properties, nlo, nbo analysis and spectroscopic characterization of gabapentin with experimental (ft-ir and ft-raman) techniques and quantum chemical calculations. Spectrochim Acta A Mol Biomol Spectrosc. 2013;109:298-307. https://doi.org/10.1016/j.saa.2013.02.035.

Yamaguchi K, Kobuniwa H, Nagami S, Bando T, Hirao A, Nakahama S, et al. Studies on synthetic ionophores. X. Transport behavior of $\mathrm{Na}^{+}$and $\mathrm{K}^{+}$with an $\omega$-hydroxy carboxylic acid containing octaether linkages as a synthetic analog of natural carboxylic acid ionophores through an organic liquid membrane. Bull the Chem Soc Jpn. 1995;68:315-321. https://doi.org/10.1246/bcsj.68.315.

\section{Captions for figures}

Figure 1. Reaction scheme and molecular structures of amino acids used in the current study

Figure 2. Retention of tocopherols in soybean oil at $180{ }^{\circ} \mathrm{C}$ : a) $\alpha-$, b) $\gamma^{-}$, and c) $\delta$ - tocopherols in soybean oil containing $5.5 \mathrm{mM}$ alanine (Ala) and alanine potassium salt (Ala K), and d) $\alpha$-, e) $\gamma$-, and f) $\delta$ - tocopherols in soybean oil containing $5.5 \mathrm{mM}$ phenylalanine (Phe) and phenylalanine potassium salt (Phe K). Error bars indicate standard deviation $(\mathrm{n}=4)$. Means not sharing a common letter are significantly different $(\mathrm{P}<0.05)$.

Figure 3. Synergism of amino acid potassium salts with mixed tocopherols in comparison with the corresponding amino acids in stripped soybean oil during heating at $180{ }^{\circ} \mathrm{C}$ for $2 \mathrm{~h}$ : a) \%loss of olefinic protons and b) \%PTAG with L-alanine (Ala) K salt, c) \%loss of olefinic protons and d) \%PTAG with L-phenylalanine (Phe) K salt, and e) \%loss of olefinic protons and f) \%PTAG with L-proline (Pro) K salt. Error bars indicate standard deviations. Means not sharing a common letter are significantly different $(\mathrm{P}<0.05)$. 
Figure 4. Antioxidant activity of amino acids or amino acid salts $(5.5 \mathrm{mM})$ during micro-frying of potato cubes at $180{ }^{\circ} \mathrm{C}$ for $8 \mathrm{~h}$ : a) \% loss of olefinic protons, b) \% loss of bisallylic protons, and c) \% polymerized triacylglycerols $(\mathrm{PTAG})$. Error bars indicate standard deviations $(\mathrm{n}=3)$. Means not sharing a common letter are significantly different $(\mathrm{P}<0.05)$.

Table 1. Antioxidant activity of $5.5 \mathrm{mM}$ amino acid, amino acid sodium salt, or amino acid potassium salt in soybean oil during 8 -h heating at $180{ }^{\circ} \mathrm{C}$.

\begin{tabular}{|c|c|c|c|c|c|}
\hline & Oxidation, $\%$ & Oxidation, \% & Oxidation, \% & Oxidation, \% & $O x$ \\
\hline & PTAG & Loss of olefinic $\mathbf{H}$ & Loss of olefinic $\mathbf{H}$ & Loss of bisallylic $\mathbf{H}$ & \\
\hline L-alanine & $8.6 \pm 0.2$ & $8.6 \pm 0.2$ & $13.0 \pm 0.1$ & $13.0 \pm 0.1$ & \\
\hline L-alanine $\mathrm{Na}$ salt & $7.9 \pm 0.2$ atc & $7.9 \pm 0.2$ atc & $12.1 \pm 0.2 \mathrm{ac}^{*}$ & $12.1 \pm 0.2 \mathrm{ac}^{*}$ & 14 \\
\hline L-alanine K salt & $5.5 \pm 0.3$ atcn & $5.5 \pm 0.3$ atcn & $10.4 \pm 0.5$ atcn $^{*}$ & $10.4 \pm 0.5$ atcn* & 1. \\
\hline L-arginine & $6.3 \pm 0.3$ & $6.3 \pm 0.3$ & $11.5 \pm 0.7$ & $11.5 \pm 0.7$ & 4 \\
\hline L-arginine $\mathrm{Na}$ salt & $5.1 \pm 0.2$ atc & $5.1 \pm 0.2$ atc & $11.2 \pm 0.9 \mathrm{c}$ & $11.2 \pm 0.9 \mathrm{c}$ & 3. \\
\hline L-asparagine & $8.8 \pm 0.4$ & $8.8 \pm 0.4$ & $14.5 \pm 0.3$ & $14.5 \pm 0.3$ & 8. \\
\hline L-asparagine Na salt & $7.4 \pm 0.3$ atc & $7.4 \pm 0.3$ atc & $13.9 \pm 0.7 \mathrm{tc}$ & $13.9 \pm 0.7 \mathrm{tc}$ & 6 . \\
\hline L-glutamine & $9.9 \pm 0.6$ & $9.9 \pm 0.6$ & $13.8 \pm 0.8$ & $13.8 \pm 0.8$ & 7 \\
\hline L-glutamine Na salt & $10.1 \pm 0.4 \mathrm{c}$ & $10.1 \pm 0.4 \mathrm{c}$ & $14.1 \pm 0.2 \mathrm{tc}$ & $14.1 \pm 0.2$ tc & 7. \\
\hline L-glutamine K salt & $7.7 \pm 0.6$ atcn & $7.7 \pm 0.6$ atcn & $12.6 \pm 1.3 \mathrm{c}$ & $12.6 \pm 1.3 \mathrm{c}$ & 5 \\
\hline L-glutamic acid & $10.7 \pm 0.6$ & $10.7 \pm 0.6$ & $15.8 \pm 0.1$ & $15.8 \pm 0.1$ & 9 \\
\hline L-glutamic acid mono Na salt & $10.3 \pm 0.5 \mathrm{tc}$ & $10.3 \pm 0.5$ tc & $14.6 \pm 0.2$ atc & $14.6 \pm 0.2 \mathrm{atc}$ & 8 \\
\hline L-glutamic acid di Na salt & $9.0 \pm 0.4 \mathrm{ac}$ & $9.0 \pm 0.4 \mathrm{ac}$ & $13.2 \pm 0.9 \mathrm{ac}$ & $13.2 \pm 0.9 \mathrm{ac}$ & \\
\hline L-phenylalanine & $8.2 \pm 0.5$ & $8.2 \pm 0.5$ & $12.9 \pm 0.6$ & $12.9 \pm 0.6$ & 5 \\
\hline L-phenylalanine Na salt & $7.3 \pm 0.5$ atc & $7.3 \pm 0.5$ atc & $11.6 \pm 0.5 \mathrm{ac}$ & $11.6 \pm 0.5 \mathrm{ac}$ & 14 \\
\hline L-phenylalanine K salt & $4.2 \pm 0.3$ atcn & $4.2 \pm 0.3$ atcn & $9.4 \pm 0.2$ atcn & $9.4 \pm 0.2$ atcn & 10. \\
\hline L-proline & $9.0 \pm 0.7$ & $9.0 \pm 0.7$ & $13.1 \pm 0.6$ & $13.1 \pm 0.6$ & 15 \\
\hline L-proline Na salt & $6.6 \pm 0.5 \mathrm{ac}$ & $6.6 \pm 0.5 \mathrm{ac}$ & $11.2 \pm 0.6 \mathrm{ac}$ & $11.2 \pm 0.6 \mathrm{ac}$ & 13. \\
\hline L-proline K salt & $5.2 \pm 0.4$ atcn & $5.2 \pm 0.4$ atcn & $10.6 \pm 0.3$ atc & $10.6 \pm 0.3$ atc & 11. \\
\hline tyrosine & $11.2 \pm 0.6$ & $11.2 \pm 0.6$ & $14.7 \pm 0.6$ & $14.7 \pm 0.6$ & \\
\hline tyrosine Na salt & $8.5 \pm 0.2$ atc & $8.5 \pm 0.2$ atc & $14.4 \pm 0.8 \mathrm{t}$ & $14.4 \pm 0.8 \mathrm{t}$ & 16 \\
\hline TBHQ $(0.02 \%)$ & $9.5 \pm 0.1$ & $9.5 \pm 0.1$ & $12.4 \pm 0.1$ & $12.4 \pm 0.1$ & \\
\hline Control & $11.9 \pm 0.5$ & $11.9 \pm 0.5$ & $15.3 \pm 0.1$ & $15.3 \pm 0.1$ & \\
\hline
\end{tabular}

Olefinic H \& Bisallylic H indicate \%loss of these protons in NMR spectrum.

PTAG: Polymerized triacylglycerols analyzed by gel permeation chromatography.

* Letters, a, t, c and $\mathrm{n}$ indicate that values are significantly different $(\mathrm{P}<0.05)$ from the corresponding amino acid (a), 0.02\% TBHQ (t), the control (c), and the corresponding Na salt (n).

$* * 100 \% \times(\mathrm{a}-\mathrm{b}) / \mathrm{a}$, a: value of control, b: value of treatment

Table 2. Analyses of fatty acids, tocopherols, and tocotrienols of vegetable oils.

Fatty acid composition (\%)

\begin{tabular}{lll}
\hline Oil & C16:0 & C16:1 \\
Olive Oil & $11.92 \pm 0.02$ & $0.87 \pm 0.00$ \\
Canola Oil & $4.04 \pm 0.01$ & $0.20 \pm 0.00$ \\
HO SBO & $6.18 \pm 0.01$ & $0.09 \pm 0.00$ \\
Avocado Oil & $14.47 \pm 0.05$ & $4.16 \pm 0.01$
\end{tabular}


Corn Oil

SBO

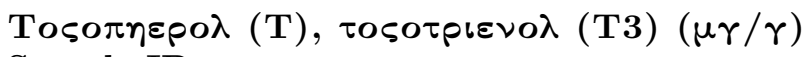

Sample ID

Olive oil

Canola oil

HO SBO

Avocado oil

Corn oil

SBO
$11.62 \pm 0.04$

$10.85 \pm 0.03$

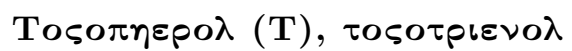

$\alpha-\mathrm{T}$

$145.96 \pm 0.34$

$179.99 \pm 0.60$

$78.24 \pm 0.13$

$150.26 \pm 1.36$

$128.17 \pm 0.95$

$98.47 \pm 0.09$
$0.08 \pm 0.00$

$0.08 \pm 0.00$

(T3) $(\mu \gamma / \gamma)$

$\alpha-\mathrm{T}$

$145.96 \pm 0.3$

$179.99 \pm 0.6$

$78.24 \pm 0.13$

$150.26 \pm 1.3$

$128.17 \pm 0.9$

$98.47 \pm 0.09$

nd: not detected; HO SBO: high oleic soybean oil; SBO: soybean oil

Table 3. Antioxidant activity of $5.5 \mathrm{mM}$ phenylalanine (Phe) or phenylalanine potassium salt (Phe K) in other vegetable oils than soybean oil heated at $180{ }^{\circ} \mathrm{C}$ for $8 \mathrm{~h}$.

\begin{tabular}{llllll}
\hline & & Oxidation, \% & Oxidation, \% & Oxidation, \% & Comparison with control (c) \\
\hline Oil & Antioxidant & PTAG & Loss of olefinic $\mathbf{H}$ & Loss of allylic H & \\
Olive oil & None & $15.41 \pm 0.16 \mathrm{a}$ & $19.99 \pm 0.34 \mathrm{a}$ & $16.53 \pm 0.00 \mathrm{a}$ & \\
Olive oil & Phe & $12.58 \pm 0.22 \mathrm{~b}$ & $17.82 \pm 1.00 \mathrm{ab}$ & $14.69 \pm 1.28 \mathrm{a}$ & \\
Olive oil & Phe K & $7.51 \pm 0.39 \mathrm{c}$ & $15.23 \pm 0.98 \mathrm{~b}$ & $10.70 \pm 0.50 \mathrm{~b}$ & \\
Canola oil & None & $10.63 \pm 0.53 \mathrm{a}$ & $13.21 \pm 0.68 \mathrm{a}$ & $8.13 \pm 0.47 \mathrm{a}$ & \\
Canola oil & Phe & $8.90 \pm 0.37 \mathrm{~b}$ & $12.91 \pm 0.20 \mathrm{a}$ & $8.10 \pm 0.38 \mathrm{a}$ \\
Canola oil & Phe K & $8.18 \pm 0.12 \mathrm{~b}$ & $12.59 \pm 0.16 \mathrm{a}$ & $6.95 \pm 0.40 \mathrm{a}$ & \\
HO SBO & None & $9.45 \pm 0.50 \mathrm{a}$ & $13.27 \pm 1.07 \mathrm{a}$ & $9.62 \pm 0.91 \mathrm{a}$ & \\
HO SBO & Phe & $4.19 \pm 0.20 \mathrm{~b}$ & $7.22 \pm 0.40 \mathrm{~b}$ & $4.73 \pm 0.29 \mathrm{~b}$ & \\
HO SBO & Phe K & $1.26 \pm 0.19 \mathrm{c}$ & $2.43 \pm 0.05 \mathrm{c}$ & $0.95 \pm 0.07 \mathrm{c}$ & \\
Avocado oil & None & $14.45 \pm 1.03 \mathrm{a}$ & $16.65 \pm 0.75 \mathrm{a}$ & $11.47 \pm 1.25 \mathrm{a}$ & \\
Avocado oil & Phe & $14.21 \pm 0.31 \mathrm{a}$ & $15.64 \pm 0.32 \mathrm{a}$ & $11.07 \pm 0.80 \mathrm{a}$ & \\
Avocado oil & Phe K & $9.49 \pm 0.14 \mathrm{~b}$ & $15.61 \pm 0.62 \mathrm{a}$ & $10.77 \pm 0.36 \mathrm{a}$ & \\
Corn oil & None & $17.93 \pm 0.32 \mathrm{a}$ & $18.25 \pm 2.02 \mathrm{a}$ & $21.56 \pm 1.57 \mathrm{a}^{*}$ & \\
Corn oil & Phe & $18.06 \pm 0.61 \mathrm{a}$ & $16.57 \pm 0.47 \mathrm{a}$ & $19.32 \pm 0.12 \mathrm{ab}$ & \\
Corn oil & Phe K & $17.01 \pm 0.91 \mathrm{a}$ & $16.19 \pm 0.56 \mathrm{a}$ & $17.01 \pm 0.41 \mathrm{~b}^{*}$ & \\
\hline
\end{tabular}

Means not sharing a common letter are significantly different $(\mathrm{P}<0.05)$ in comparison between treatments in each oil.

*Bisallylic protons were determined for corn oil.

** $100 \% \times(\mathrm{a}-\mathrm{b}) / \mathrm{a}$, a: value of control, b: value of treatment

nd: not detected; HO SBO: high oleic soybean oil; SBO: soybean oil

Table 4. Correlation ( $\mathrm{r}$ values) and correlation probability ( $\mathrm{p}$ values) between oxidation of SBO containing $5.5 \mathrm{mM}$ phenylamine (Phe) or phenylalanine potassium salt (Phe K) and major fatty acids or tocopherols.

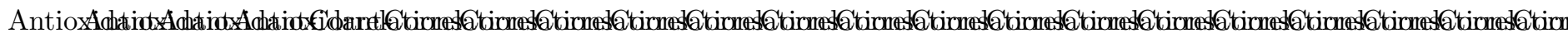

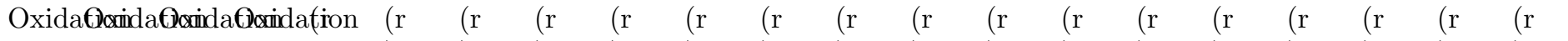
valuesyaluesyaluesyaluesyaluesyaluesyaluesyaluesyaluesyaluesyaluesyaluesyaluesyaluesyaluesyaluesyalu C16:0 C16:0 C16:0 C18:1 C18:1 C18:1 C18:2 C18:2 C18:2 C18:2 Sat./usisat.usisat.umasat. $\alpha-\quad \alpha-\quad \gamma-$

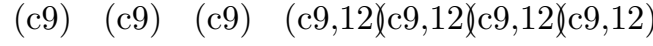

tocoplterolplterolpherol 
Phe- Phe- Phe- - $\quad$ - $\quad$ - $\quad$ - $\quad$ 0.18110.18110.1811

OlefinOlefindlefint:28230.28230.28230.2823

$\mathrm{H} \quad \mathrm{H} \quad \mathrm{H}$

Phe- Phe- Phe- - $\quad$ - $\quad$ - $\quad$ - $\quad$ - $\quad 0.23610 .23610 .2361$

PTAGPTAGPTAG0.49960.49960.49960.4996

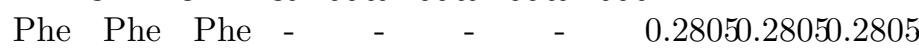

K- K- K- 0.32960.32960.32960.3296

Olefindlefindlefinic

$\mathrm{H} \quad \mathrm{H} \quad \mathrm{H}$

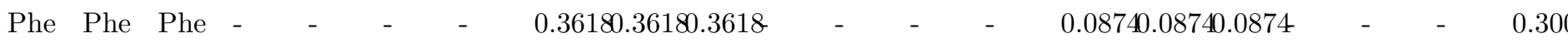

$\begin{array}{llllll}\text { K- } \quad \mathrm{K}-\quad \mathrm{K}- & 0.19360 .19360 .19360 .1936 & 0.39380 .39380 .39380 .3938 & 0.71940 .71940 .7194\end{array}$

PTAGPTAGPTAG

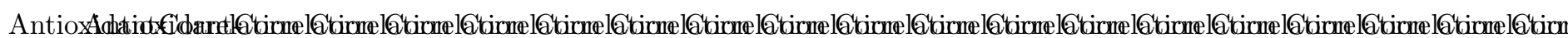

OxidaAximdapioub- prob- prob- prob- prob- prob- prob- prob- prob- prob- prob- prob- prob- prob- prob- prob- prob- prob- prob $\begin{array}{lllllllllllllllllll}\text { a- } & \text { a- } & \text { a- } & \text { a- } & \text { a- } & \text { a- } & \text { a- } & \text { a- } & \text { a- } & \text { a- } & \text { a- } & \text { a- } & \text { a- } & \text { a- } & \text { a- } & \text { a- } & \text { a- } & \text { a- } & \text { a- } \\ \text { bil- } & \text { bil- } & \text { bil- } & \text { bil- } & \text { bil- } & \text { bil- } & \text { bil- } & \text { bil- } & \text { bil- } & \text { bil- } & \text { bil- } & \text { bil- } & \text { bil- } & \text { bil- } & \text { bil- } & \text { bil- } & \text { bil- } & \text { bil- } & \text { bil- } \\ \text { ity } & \text { ity } & \text { ity } & \text { ity } & \text { ity } & \text { ity } & \text { ity } & \text { ity } & \text { ity } & \text { ity } & \text { ity } & \text { ity } & \text { ity } & \text { ity } & \text { ity } & \text { ity } & \text { ity } & \text { ity } & \text { ity } \\ (\mathrm{p} & (\mathrm{p} & (\mathrm{p} & (\mathrm{p} & (\mathrm{p} & (\mathrm{p} & (\mathrm{p} & (\mathrm{p} & (\mathrm{p} & (\mathrm{p} & (\mathrm{p} & (\mathrm{p} & (\mathrm{p} & (\mathrm{p} & (\mathrm{p} & (\mathrm{p} & (\mathrm{p} & (\mathrm{p} & (\mathrm{p}\end{array}$

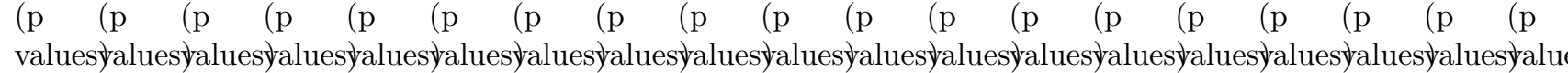

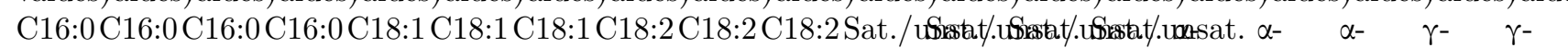

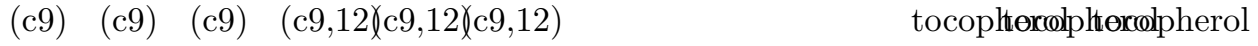

tocophercol

Phe- Phe- Phe- 0.58790.58790.58790.58790.73140.73140.73140.79150.79150.79150.79150.93040.93040.93040.00940.00940.00940.220 Olefindlefindlefinic

$\begin{array}{lll}\mathrm{H} & \mathrm{H} & \mathrm{H}\end{array}$

Phe- Phe- Phe- 0.31300.31300.31300.31300.65250.65250.65250.66860.66860.66860.66860.68070.68070.68070.09280.09280.09280.20: PTAGPTAGPTAG

Phe Phe Phe 0.52350.52350.52350.52350.59030.59030.59030.65390.65390.65390.65390.86660.86660.86660.02220.02220.02220.278

K- K- K-

Olefindlefindlefinic

$\mathrm{H} \quad \mathrm{H} \quad \mathrm{H}$

Phe Phe Phe 0.71320.71320.71320.71320.48100.48100.48100.43980.43980.43980.43980.86920.86920.86920.10710.10710.10710.56

K- K- K-

PTAGPTAGPTAG

Figure 1.

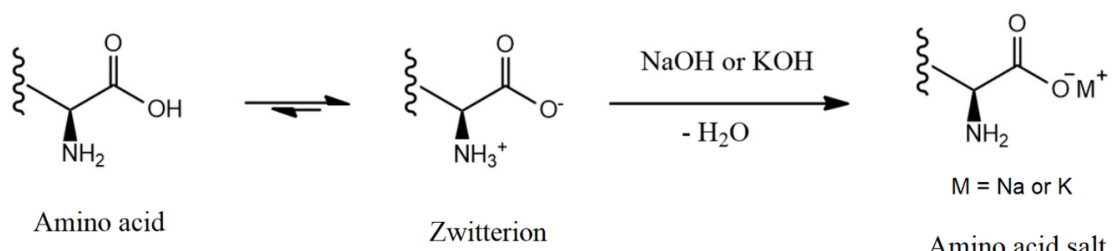


<smiles>C[C@H](N)C(=O)O</smiles>

L-alanine<smiles>NC(=O)C[C@H](N)C(=O)O</smiles>

L-asparagine<smiles>NC(=O)CC[C@H](N)C(=O)O</smiles>

L-glutamine<smiles>O=C(O)[C@@H]1CCCN1</smiles>

L-proline<smiles>N=C(N)NCCC[C@H](N)C(=O)O</smiles>

L-arginine<smiles>N[C@@H](CCC(=O)O)C(=O)O</smiles>

L-glutamic acid<smiles>N[C@@H](Cc1ccccc1)C(=O)O</smiles>

L-phenylalanine<smiles>N[C@@H](Cc1ccc(O)cc1)C(=O)O</smiles>

L-tyrosine

Figure 2 . 


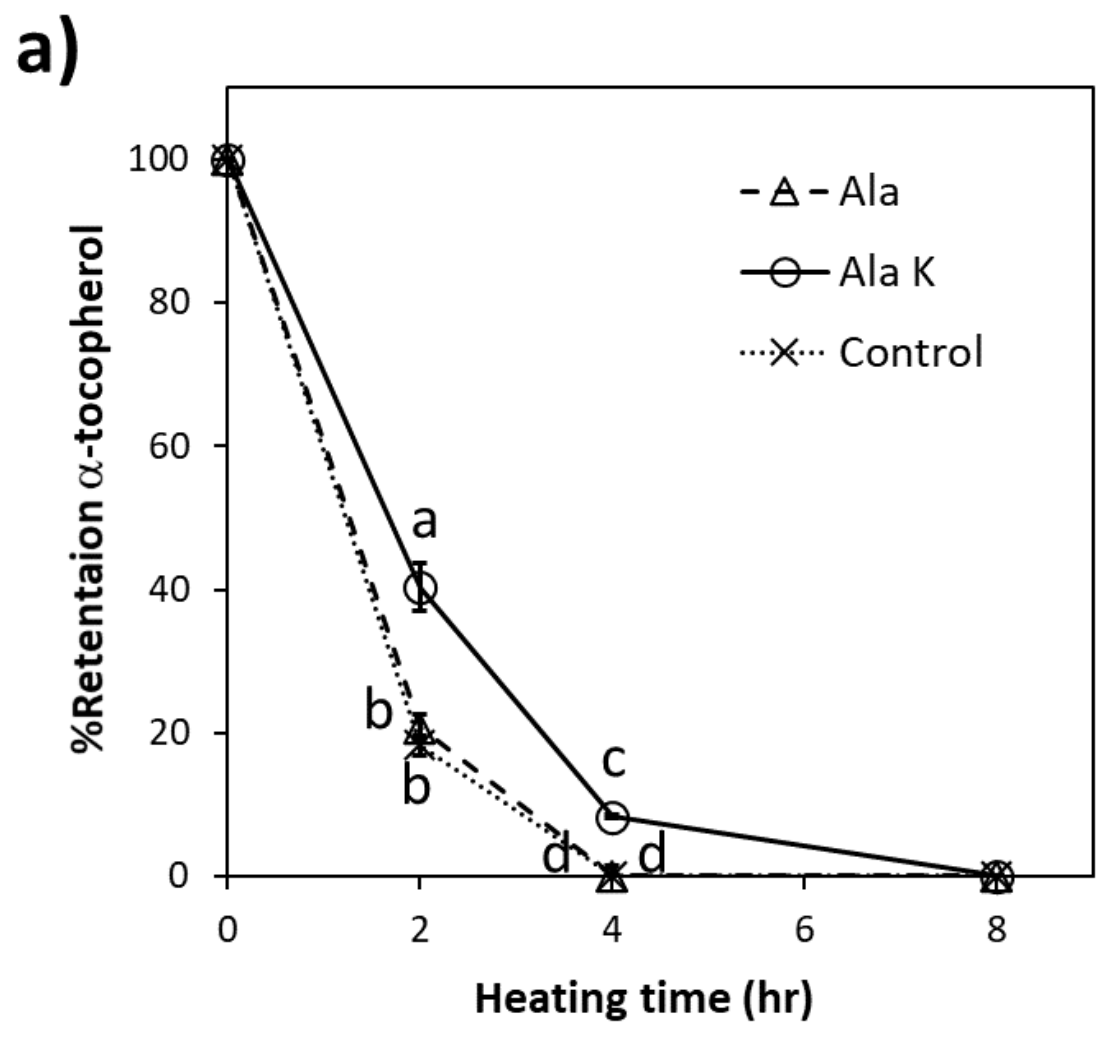




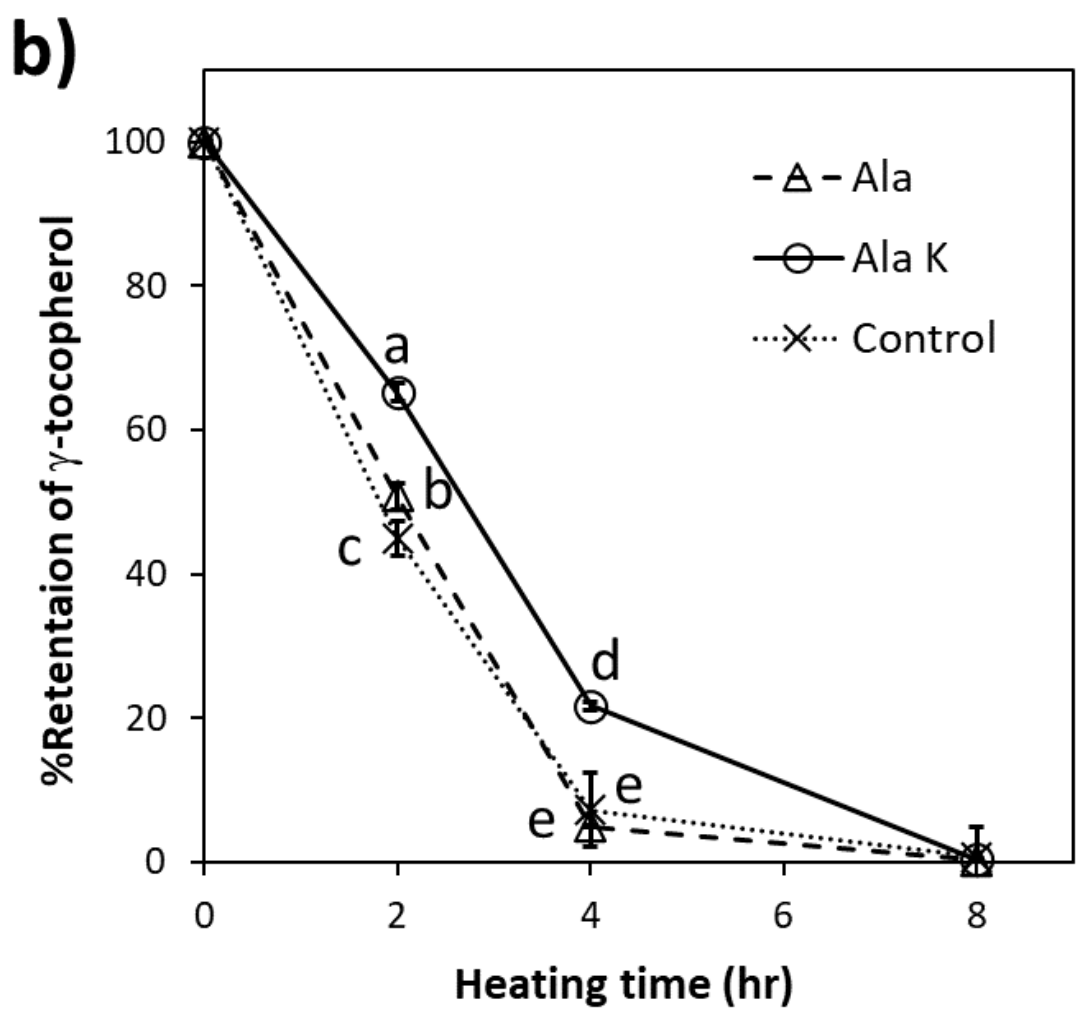




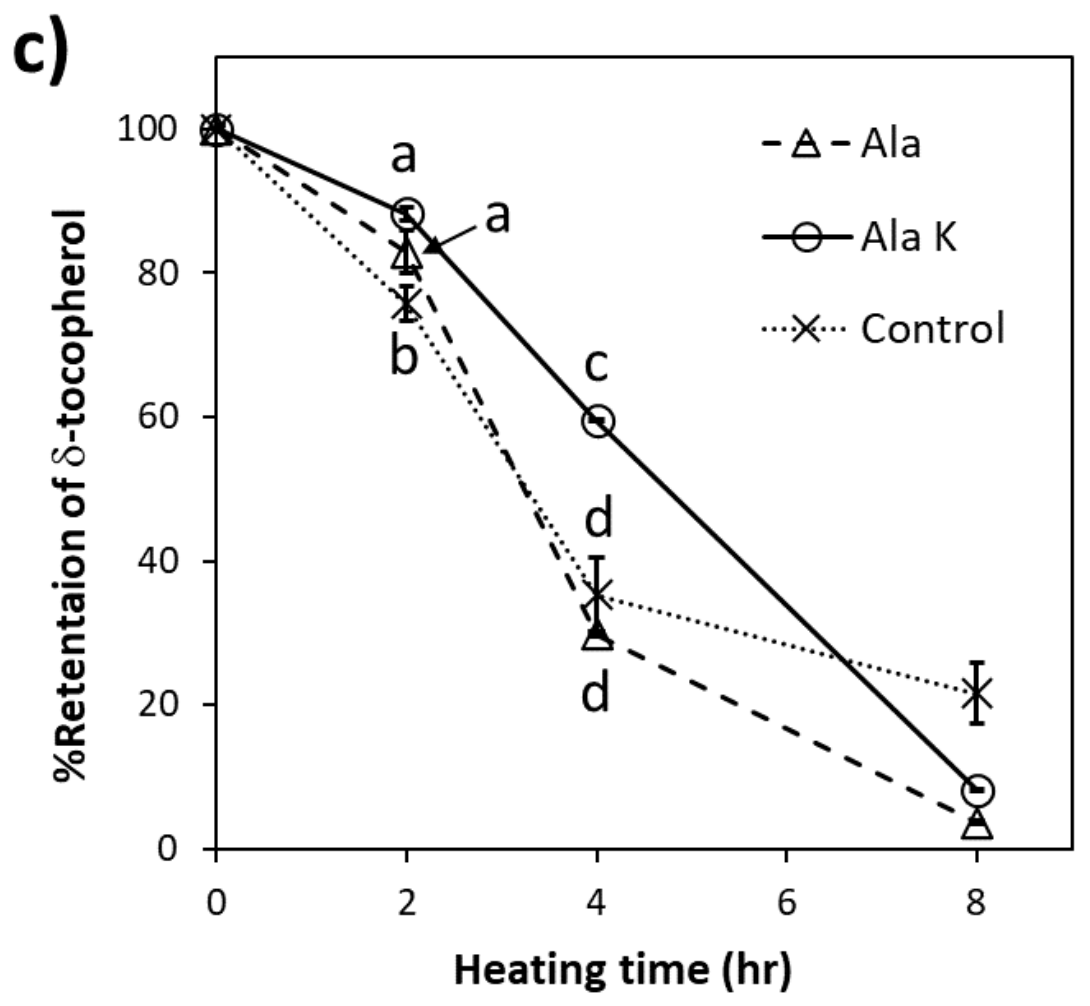




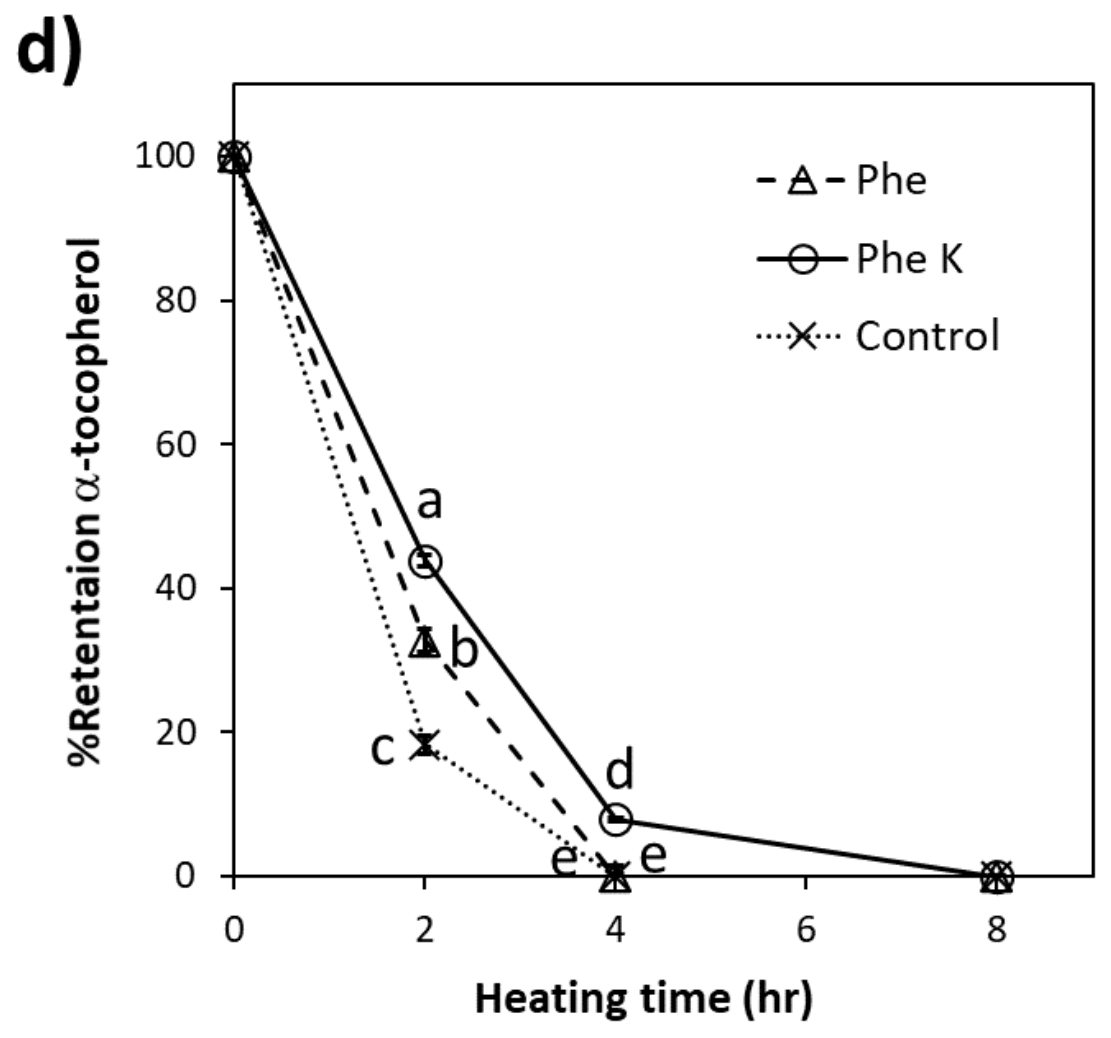




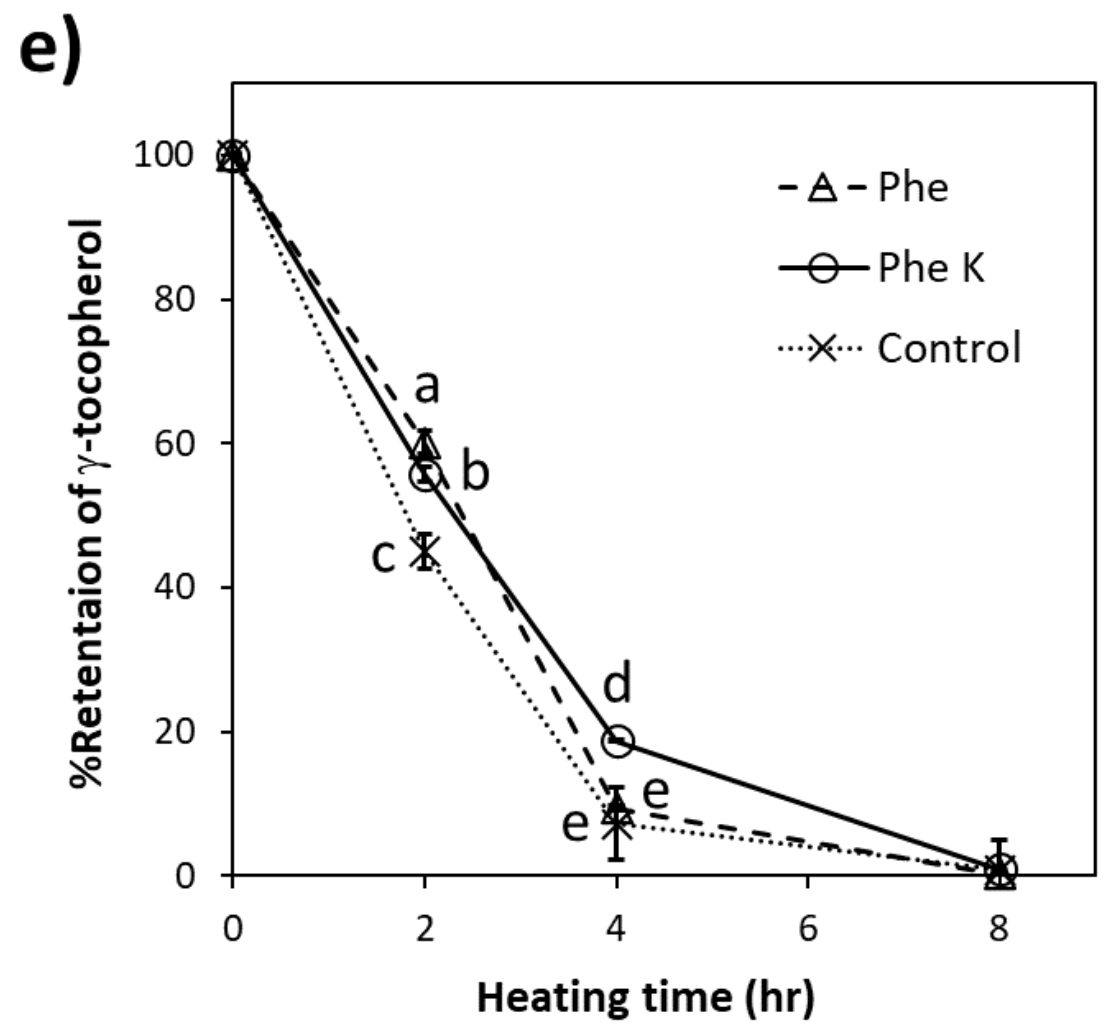


f)

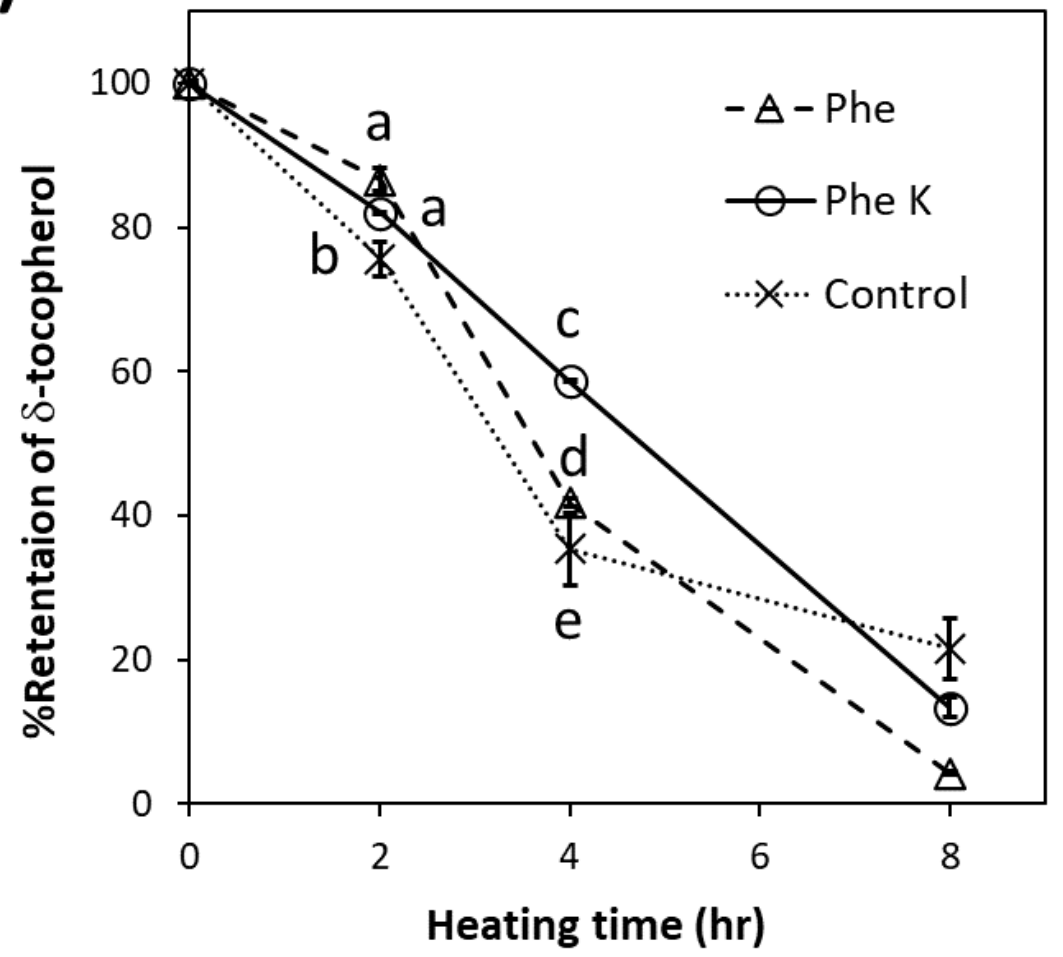

Figure 3 .

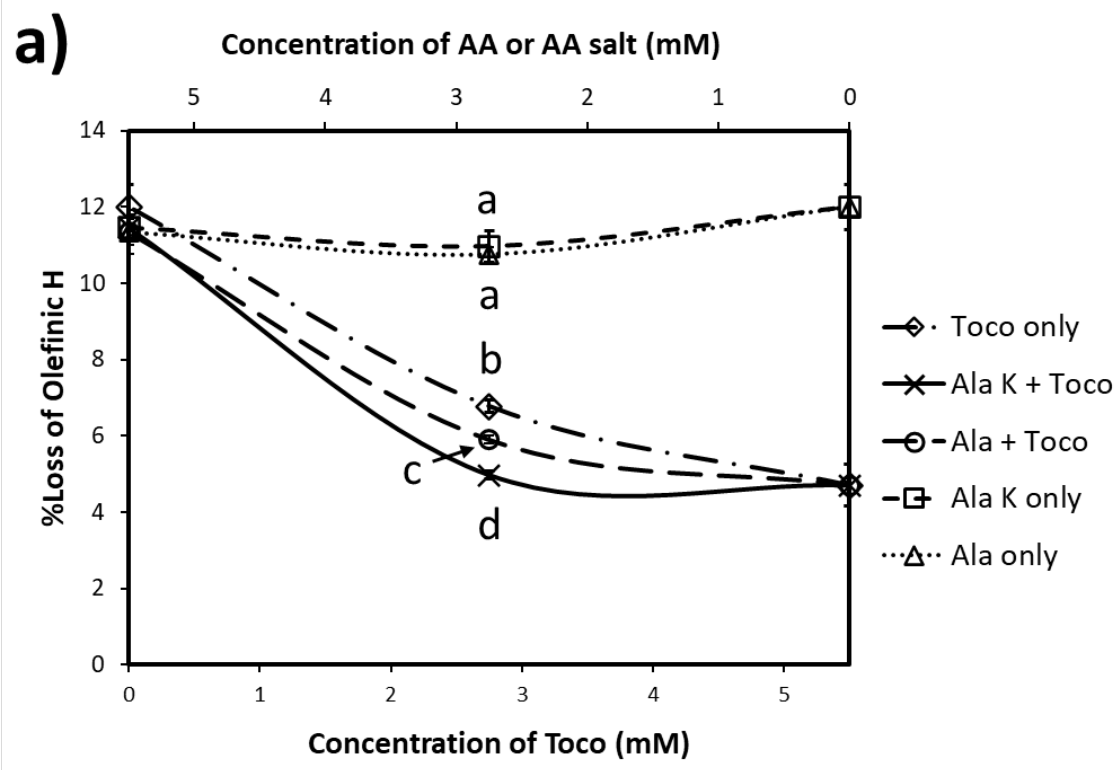



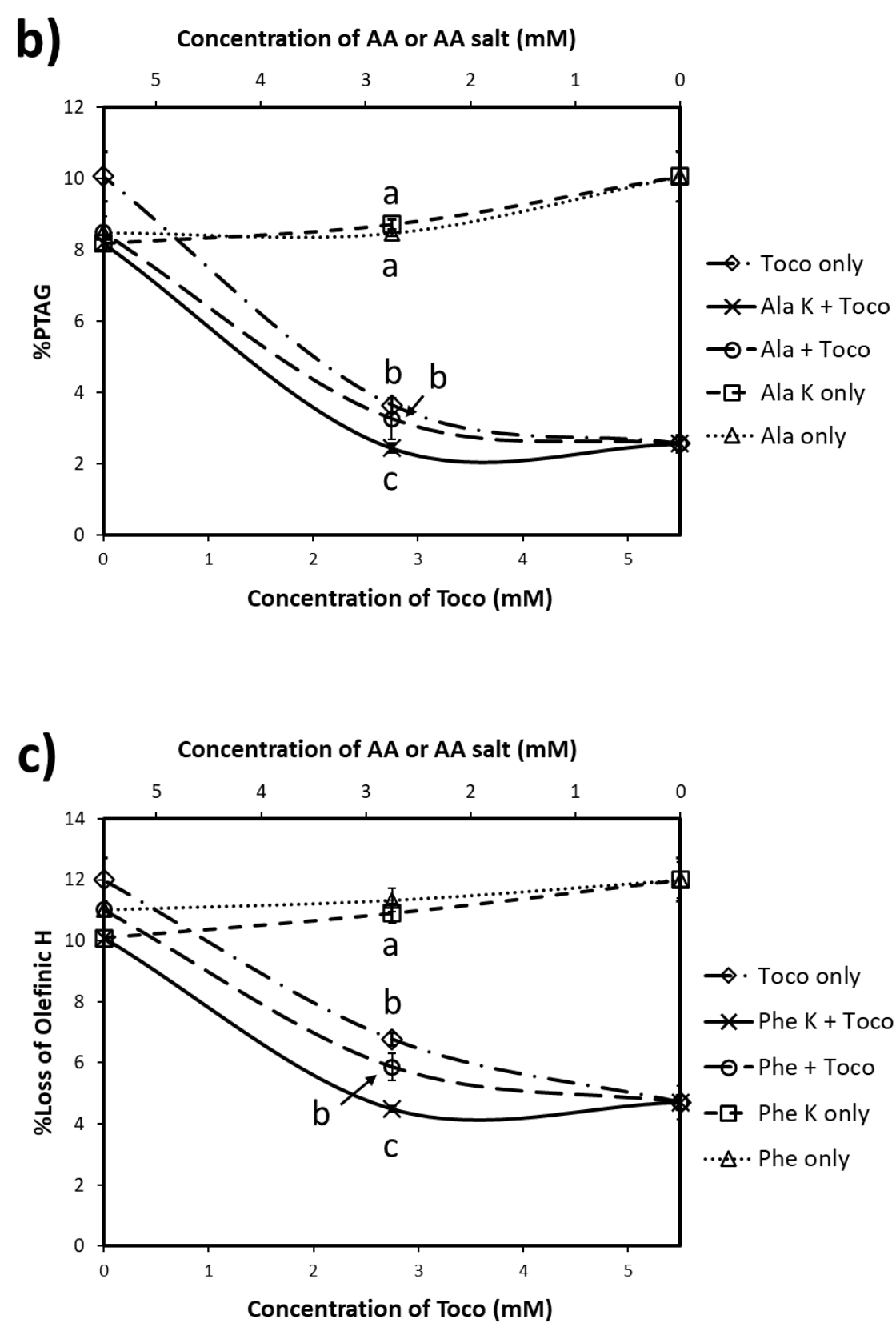

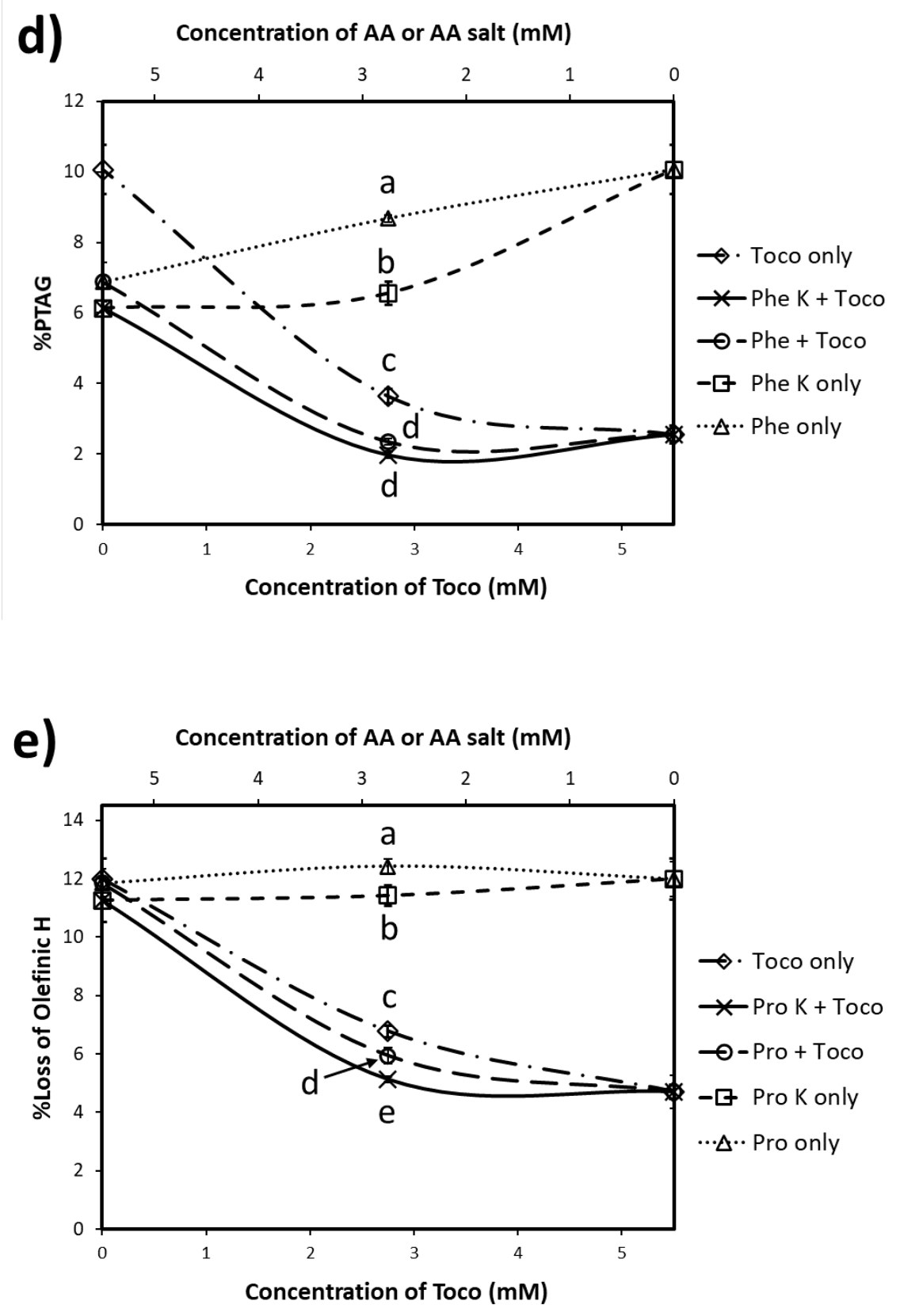


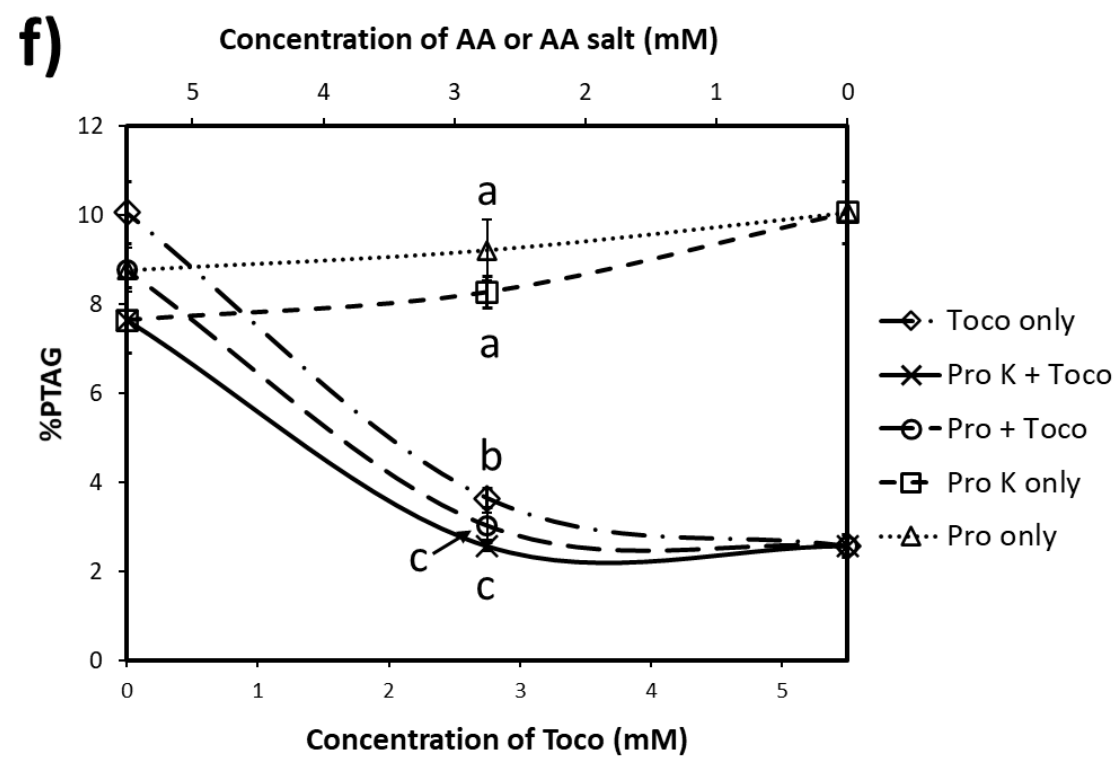

Figure 4.

a)

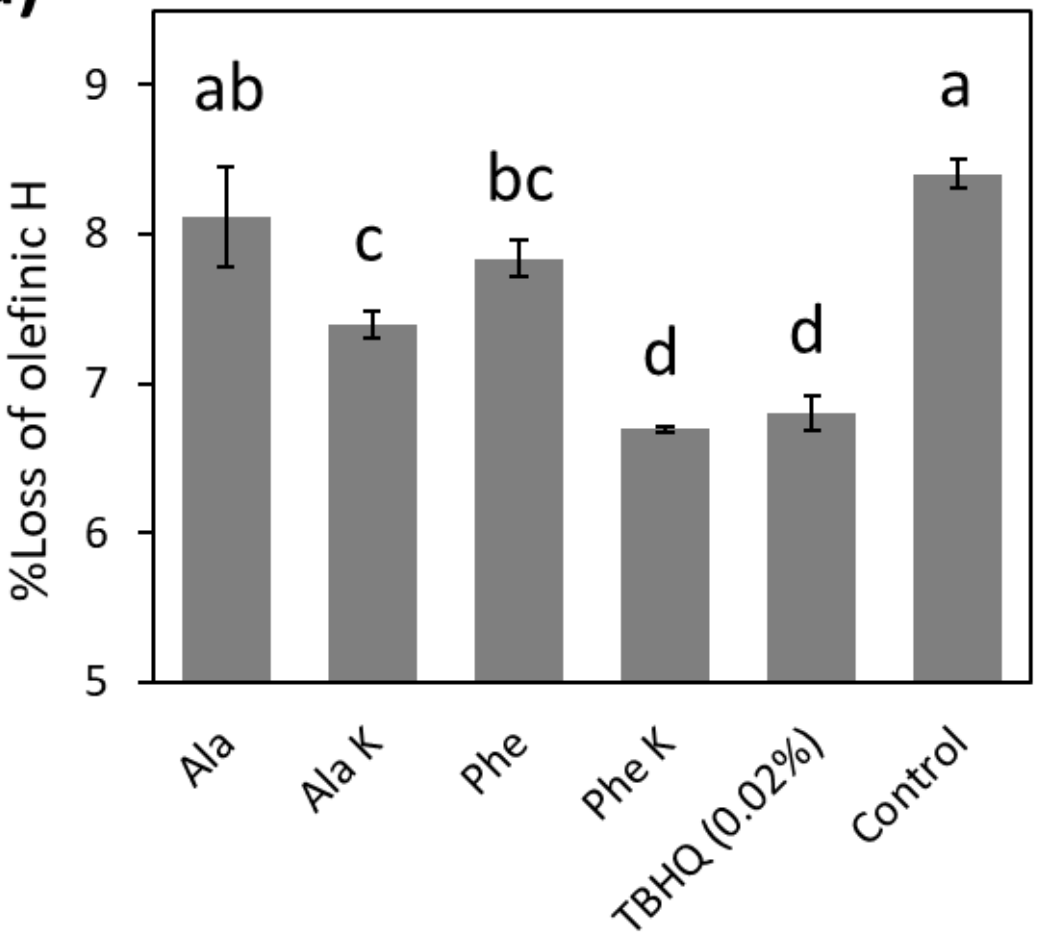


b)

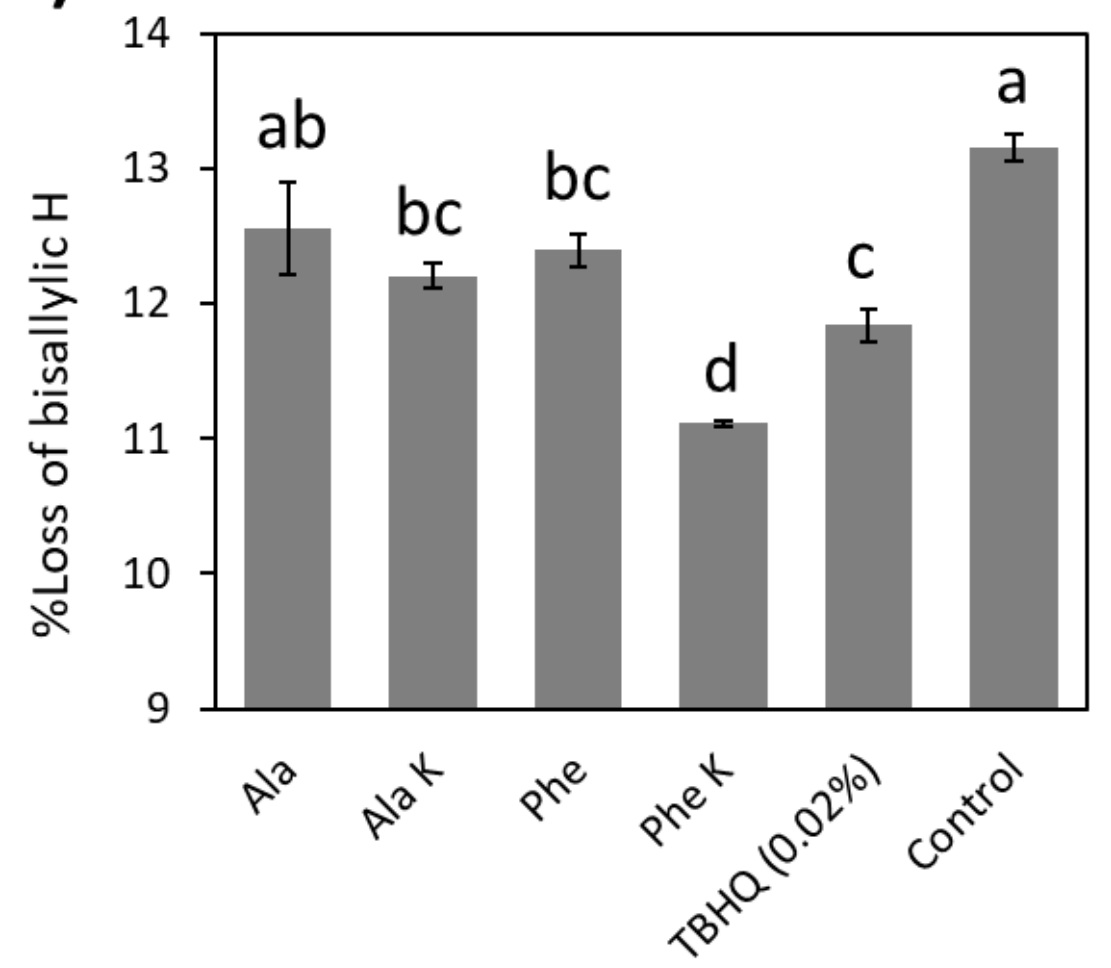




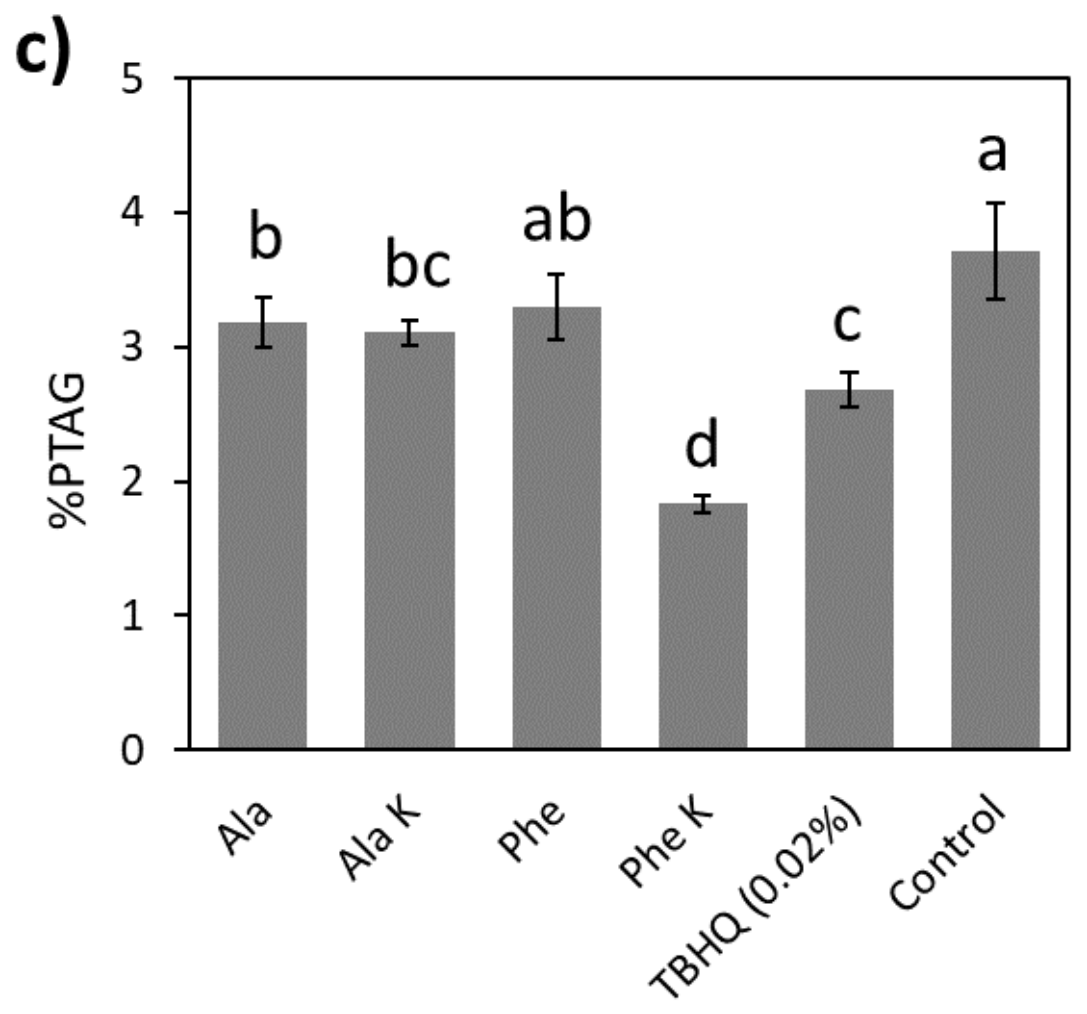

